\title{
Residential Solar Water Heater Adoption Behaviour: A Review of Economic and Technical Predictors and Their Correlation with the Adoption Decision
}

\author{
Sara Ghaboulian Zare ${ }^{1}\left(\mathbb{D}\right.$, Reza Hafezi $^{2}\left(\mathbb{D}\right.$, Mohammad Alipour $^{3,4} * * \mathbb{D}$, Reza Parsaei Tabar $^{5}(\mathbb{D}$ \\ and Rodney A. Stewart ${ }^{3,4}{ }_{\mathbb{D}}$ \\ 1 Industrial Engineering Department, Sadjad University, Mashhad 91886, Iran; s.ghaboolian25@gmail.com \\ 2 Science and Technology Futures Studies, National Research Institute for Science Policy, \\ Tehran 1435894461, Iran; hafezi@nrisp.ac.ir \\ 3 School of Engineering and Built Environment, Griffith University, Southport, QLD 4222, Australia; \\ r.stewart@griffith.edu.au \\ 4 Cities Research Institute, Griffith University, Southport, QLD 4222, Australia \\ 5 Faculty of Administrative Sciences and Economics, Ferdowsi University, Mashhad 91779, Iran; \\ reza.parsa.d@gmail.com \\ * Correspondence: mohammad.alipour@griffithuni.edu.au; Tel.: +61-40-435-2223
}

check for

Citation: Ghaboulian Zare, S.;

Hafezi, R.; Alipour, M.; Parsaei Tabar,

R.; Stewart, R.A. Residential Solar

Water Heater Adoption Behaviour: A

Review of Economic and Technical

Predictors and Their Correlation with

the Adoption Decision. Energies 2021,

14, 6630. https://doi.org/10.3390/

en14206630

Academic Editor: Antonio Rosato

Received: 3 August 2021

Accepted: 8 October 2021

Published: 14 October 2021

Publisher's Note: MDPI stays neutral with regard to jurisdictional claims in published maps and institutional affiliations.

Copyright: (c) 2021 by the authors. Licensee MDPI, Basel, Switzerland. This article is an open access article distributed under the terms and conditions of the Creative Commons Attribution (CC BY) license (https:/ / creativecommons.org/licenses/by/ $4.0 /)$.

\begin{abstract}
The successful deployment of the solar water heater (SWH) in the residential sector relies on the household's bounded rational decision-makers to accept this system. The decision is shaped by a wide spectrum of predictors that form heterogeneous behaviour. Over the past years, research has employed a wide range of these predictors to understand their role in the decision and predict the behaviour and diffusion rate of SWHs. This review primarily identifies economic and technical predictors of 100 quantitative and qualitative studies on the residential SWH adoption decision. For the identified predictors, their characteristics and popularity are explored in a structured and coherent framework. The review further investigates the correlation between the identified predictors and the adoption decision from 97 of the 100 initially reviewed studies. The outcome of the research revealed 123 (56 economic and 67 technical) predictors that were classified into seven categories. 'Financial incentives' and 'perceived attitude towards government policies' are among the most popular economic predictors, whereas 'house type' and 'knowledge of $\mathrm{SWH}^{\prime}$ were the most frequent technical factors in the research. Analysing the correlation between 99 predictors and the decision also unfolded that certain attitudinal attributes have a stronger influence on the residential SWH take-up than some common factors (e.g., electricity cost, technical variables).
\end{abstract}

Keywords: solar water heater; adoption behaviour; household; predictors; technology innovation

\section{Introduction}

Promising renewable energy (RE) systems have ushered in a transition towards a green, low-carbon, and climate-resilient society. Among the available RE systems, solar water heaters (SWHs) are a well-established technology that has been developed worldwide in response to energy poverty, pollution, and climate change [1,2]. The production of hot water using an SWH is one of the most prominent uses of solar energy, where thermal energy from solar radiation is converted into heat for use in various water heating applications [3]. Over the past three decades, environmentally friendly SWH systems have become increasingly affordable, technically reliable, and in many areas, are now on the threshold of mass-market uptake. As the technology has been embraced in both developed as well as remote and off-grid areas, governments worldwide have vested interests in the installation and use of domestic SWHs.

Despite the wide range of policies in place, the uptake of home SWHs has remained low in many areas. Efforts to promote these systems in the residential sector through finan- 
cial support and the triggering of environmental values have thus far led to inconsistent and contradictory implications. Beyond the incentives and managerial interventions are heterogeneous households, who are the final and main decision-makers in the uptake decision-making process [4,5]. Their adoption decision behaviour determines the extent to which any assertive deployment policies translate into success [6]. The central role of household behaviour towards the adoption of SWHs has attracted the attention of researchers. Accordingly, studies have investigated various dimensions of the heterogeneous, heuristic behaviour of households and predicted their diffusion rate of the innovation for long-term policies. A wide range of predictors (in this study, variables, characteristics, factors, parameters, indicators, and determinants interchangeably refer to the 'predictors' of residential SWH system adoption) has been proposed in retroactive and futuristic studies for testing and analysing the awareness, motivation, interests, attitude, tendency, willingness, intention, and adoption decision regarding the uptake of SWHs in the hope of achieving more tangible insight. These predictors span a range of environmental, social, demographic, psychological, and personal values, but also-and more crucially-financial and technical angles. The overriding composition of economic and technological predictors has largely dominated studies on residential SWH acceptance [7-11]. Economic factors determine the final price of the systems as well as the decision-makers' purchasing power, indicating to what extent they can afford the system. Technical indicators, either directly or indirectly, profoundly influence economic dimensions, system efficiency, and performance.

Although end-user's perspectives on the adoption of SWH systems have been well established, no coherent framework has been developed for critically understanding the pivotal component of this research-namely, the predictors. While research on the predictors of SWH adoption is scarce, numerous studies have recognised the behavioural factors related to sport [12], information technology [13], solar photovoltaic (SPV) [11], medical [14,15], and technology-based products [16]. To address this gap, this study primarily sought to identify the determinants of home SWH uptake decisions with a focus on economic and technical parameters. The gleaned factors were classified in a coherent scheme and their utilisation was described; then, the popular and overlooked factors were examined closely by estimating their frequency of use. Another main objective of this study was to investigate the correlation between the identified predictors (independent variables) and adoption decision (dependent variable) to determine the significance level of the predictors on the decision. To achieve these objectives, quantitative and qualitative studies were systematically reviewed that (1) investigated the adoption and pre-adoption prospects of residential consumers towards SWH usage; (2) predicted the acceptance rates for medium to long periods; or (3) explained consumer behaviour by distinguishing the predictors' effects on adoption.

The remainder of this review is organised as follows: Section 2 describes the methods used to collect, derive, and analyse the data. The outcome of the study is presented in two sections: Section 3 reports the economic and technical predictors of SWH adoption behaviour alongside their popularity in the literature; and Section 4 examines the correlation between the identified predictors and the adoption decision. Discussion and conclusions of the study are finally provided in Section 5.

\section{Method}

This systematic quantitative literature review was performed under the Preferred Reporting Items for Systematic Reviews and Meta-Analyses (PRISMA) framework [17] (Figure 1). The PRISMA framework enabled relevant articles to be derived from among the various RE studies that exist in the literature, and further facilitated the quantitative gleaning of the factors discussed in the selected research. This review applied a comprehensive and simply reproducible systematic exploration rule. This type of review is systematic because the methods used to survey the literature and select the most relevant papers are explicit and reproducible. This means that following the method's steps will lead to similar conclusions. Qualitative, quantitative, and empirical research can be evaluated using 
this procedure; a set of variables was created from the articles, which were quantitatively displayed as tables and charts [18].

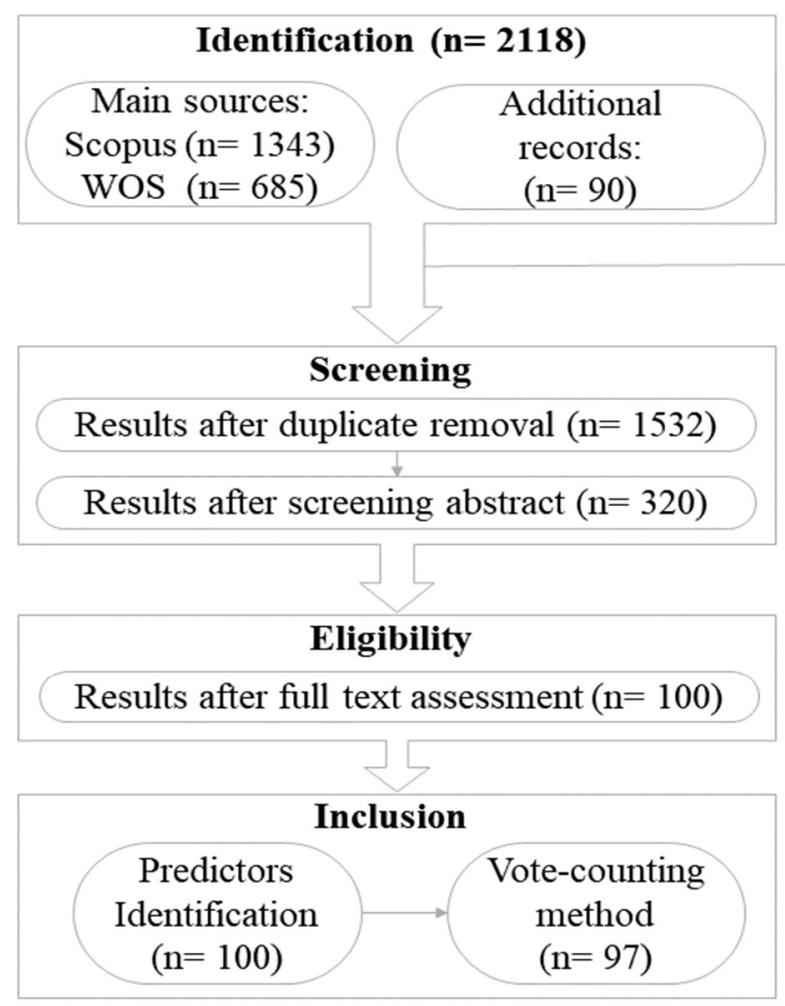

Figure 1. PRISMA flowchart depicting the stages of the study selection procedure [17].

\subsection{Paper Collection}

The study scope concentrated on only the adoption or pre-adoption phase of an individual's decision-making process in the domestic sector (Table 1). The technical predictors incorporated both SWH and solar thermal water heater (STWH) systems. The end-user category was restricted to the residential sector and, therefore, systems in public buildings such as hospitals, universities, industry, and market sectors were excluded. This study did not consider the behavioural change triggered after the SWH adoption/rejection decision stage. The methodological background of all statistical and nonstatistical methods and all quantitative and qualitative strategies fell within this research's scope. Articles containing specific technology or economic estimation techniques, risk assessment, and feasibility or optimisation studies were excluded, whereas articles containing empirical research, government and industry records, and expert perspectives concentrating on the household sector were included. Broadly, this research aimed at accurately recognising the cognate and identified variables. The primary goal was to evaluate predictors within the reviewed literature rather than the demographic information of the publications (such as the authors, journals, and study location), unlike traditional systematic literature reviews $[19,20]$. Preliminary demographic information of the selected studies is provided in the Supplementary Information File.

In the first stage, academic research papers were collected in January 2021 by searching for a combination of 46 keywords in either the abstract, title, or keywords in two main scholarly databases (Scopus and Web of science (WOS); the list of keywords is presented in the Supplementary Information File). English records published online in journals, conference proceedings, or book series were selected. Further publications were obtained by employing a snowballing data collection method (i.e., reference and citation exploration). The search under these guidelines resulted in a total of 2118 papers. After first filtering, 586 articles were removed that were reviews, book reviews, editorial materials, correlation 
studies, data papers, letters, notes, news items, meeting abstracts, errata, business articles, books, or editorials. Next, the articles' information was downloaded to the EndNote X9 software package; duplicate articles were deleted, leaving 1532 papers. Articles were then reviewed to remove those that did not have full-text access or only the title, abstract, and keywords of the article were in English. A four-step method was employed to facilitate screening and eligibility assessments (details of the method are provided in the Supplementary Information File). The initially identified studies were evaluated by their title, keywords, abstract, and full text. The use of this method within the PRISMA framework largely minimised the exclusion of any relevant articles. Screening the titles and abstracts of articles and excluding irrelevant articles resulted in 320 articles. Full-text analysis of the remaining records led to the final 100 articles that were subjected to data extraction, synthesis, and vote-counting quantitative analysis.

Table 1. Scope of the research.

\begin{tabular}{ccc}
\hline Scope & \multicolumn{1}{c}{ Inclusion } \\
\hline \multirow{2}{*}{ Technology context } & Included & Solar water heater and solar thermal water heater systems \\
\cline { 2 - 3 } End-user type & Excluded & Solar photovoltaics, solar cookers, solar-powered lanterns, and passive solar \\
\cline { 2 - 3 } & Included & Residential sector \\
\hline \multirow{2}{*}{ Behaviour } & Included & $\begin{array}{c}\text { Adoption and pre-adoption: Adoption, intention, willingness to adopt, attitude, } \\
\text { motives, awareness, knowledge, and tendency towards SWH or STWH adoption }\end{array}$ \\
\cline { 2 - 3 } & Excluded & Behaviour after the adoption stage: satisfaction level and efficiency level \\
\hline
\end{tabular}

\subsection{Data Extraction and Synthesis}

In this study, the predictors were classified into financial and technical categories. These two categories incorporated all variables that were on the subject of interest. A Microsoft Excel database was created to identify and classify the predictors and then to explore their use frequency. Factors identified from the literature were entered into the spreadsheet one by one. Before entering a new variable, each one was semantically compared with existing factors. Various terms were often found in comparison with many terms with the same meaning. For example, 'temperature' includes water inlet temperature, ambient temperature when the sun is shining, and water temperature [21,22]. Non-valueadded variables that have the same meaning were combined with a more specific term already written, even if that term was ostensibly close to another term (for example, 'installation cost' versus 'upfront cost'). Any term that did not have the same meaning and enriched the list was added separately. In qualitative articles, where the variables were in descriptive form, they were linked to the most relevant term. It should be noted that irrelevant factors related to the research's general trend were not considered in this review. For example, Alrashed et al. [23] examined the factors that affect the application of three types of RE systems (SPVs, micro-wind turbines, and SWHs). Their study investigated wind speed as a variable that influences wind energy and, thus, it was not related to SWHs; therefore, wind speed was not identified as a predictor in this review.

The synthesis of predictors after data extraction required sufficient knowledge of the concepts of each variable. Contents were selected to classify new variables without any biased personal opinion involved in the classification. Some parameters were similar in appearance, although they naturally had different meanings and had to be classified into different categories. For instance, when an article analysed a solar system's cost, the variable classification had to specify exactly what the cost definition was and what was included. This was the result of numerical calculations or solely consumers' opinions. To distinguish between these, the variables were discriminated according to their input data. In each category, the predictors were classified by whether the variables originated from experts' opinions, factual information, and research results, or adopted from end- 
users' judgements, opinions, and obtained information (Figure 2). Each leading group was subdivided into two sections based on the source of input data: perceived attitudes towards financial and technical features and financial and technical knowledge of SWH adoption. The second category's determinants were shaped by experts' or stakeholders' viewpoints or actual data carried from research or assessments. The perceived orientation determinants were raised from households' characteristics, beliefs, and information towards houses or SWH technology features. Broadly speaking, the categorisation was an evolutionary approach, which means that by identifying new predictors, the best general appropriate term was chosen to replace the previous one.

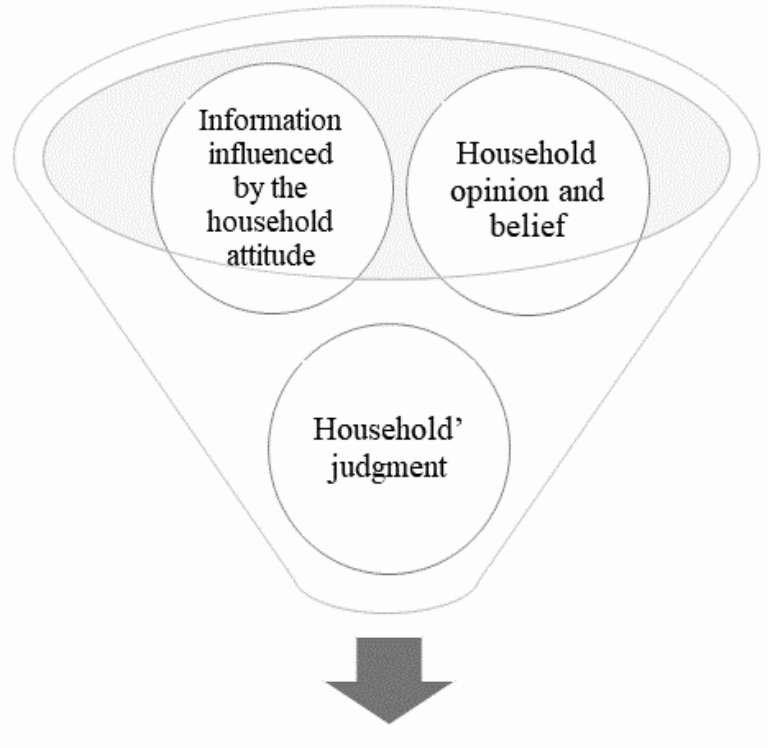

\section{Classified as:}

Perceived attitudes towards financial knowledge Perceived attitudes towards technical knowledge

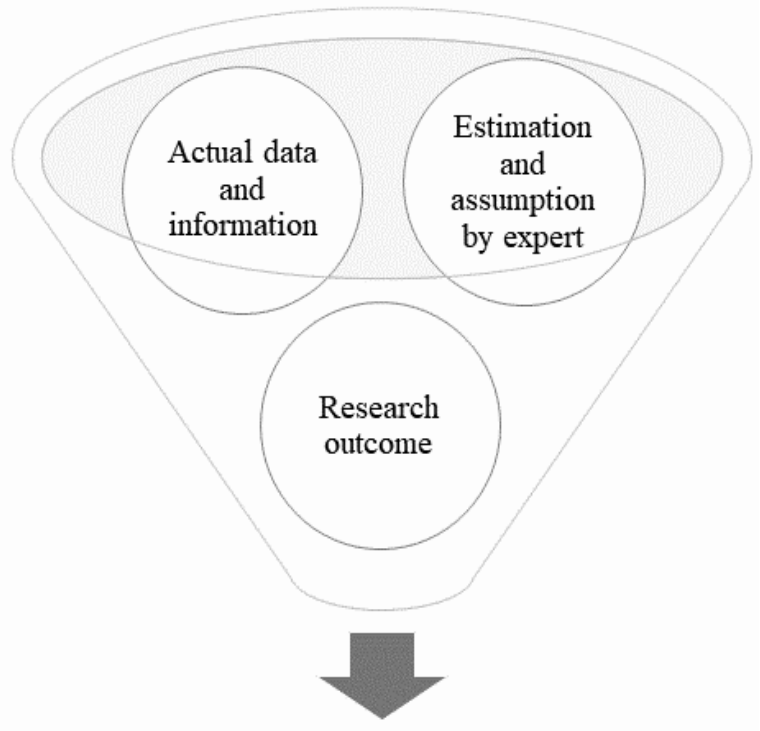

Classified as:

Financial knowledge

Technical knowledge

Figure 2. Distinction between the financial and technical predictors in both categories based on their input data.

\subsection{Frequency of Use}

The estimation of frequency of use and the recognition of factors were directed simultaneously. Once classified, a predictor was considered ' 1 ' in its corresponding cell. A subcategory with more than one variable was calculated using the number of iterations of the variables. For example, 'government financial incentives' contained various types of government policies, such as governmental grants, financial incentives, subsidies for purchase, subsidies for installation, legislation, solar RE credits, Renewable Portfolio Standard rate, and reduction of return of investment (RoI) by feed-in tariffs (FiTs). All of these were merged into only two predictors, and their repetitions exhibited all related incentives.

\subsection{Vote-Counting Method}

Widely regarded as one of the most common quantitative techniques used in research reviews, the vote-counting procedure describes studies' results for synthesising all outcomes correlated to each article $[24,25]$. This method provided insight into which independent variables were most/least correlated with the behaviour variables and their level of importance in the uptake decision. Ninety-seven quantitative and qualitative articles with either empirical or statistical data were selected to create a database for the vote-counting technique. The quantitative studies included a linear regression approach that analysed the statistical relationship (significance at $0.1 \%, 0.5 \%, 1 \%$, and $5 \%$ ) between independent and dependent parameters. However, variables in quantitative studies with 
surveys and descriptive statistical methods were translated into the most similar terms and were voted in a similar manner to qualitative studies (i.e., interviews). In qualitative studies with narrative data, the votes were limited to the variables discussed by the authors.

The vote-counting technique elicited four potential coding results from the level of the impact of the identified variables (as independent variables) on the adoption decision in the reviewed papers (Table 2): (non)significant positive and (non)significant negative relationships. In the quantitative studies, variables were evaluated based on the value of $\beta$ and $p$ and fell into one of the four codes. The parameters in the qualitative studies were categorised based on the level of arguments and inferences. All dependent and independent predictors incorporated in the vote-counting method were specified in this process in a spreadsheet and then summed over studies to detect the overall trends of (non)significance of variables. When the relationships between variables were analysed in the reverse direction (e.g., lack of knowledge), their codes were also reversed to retain consistency.

Table 2. Assessment of votes based on described coding.

\begin{tabular}{ccc}
\hline \multirow{2}{*}{ Code } & \multicolumn{2}{c}{ Interpretation } \\
\cline { 2 - 3 } & Quantitative Studies & Qualitative Studies \\
\hline -2: Significant negative connections & Negative $\beta$ and $p$ value $\leq 0.05$ & Strongly argued \\
-1: Negative connections & Negative $\beta$ and $p$ value $\geq 0.05$ & Limited knowledge, no consensus \\
$+1:$ Positive connections & Positive $\beta$ and $p$ value $\geq 0.05$ & Limited knowledge, no consensus \\
$+2:$ Significant positive connections & Positive $\beta$ and $p$ value $\leq 0.05$ & Strongly argued \\
\hline
\end{tabular}

As an example of assigning codes to predictors in qualitative research, Balezentis et al. [26] stated that the "energy efficiency of installations is important for $67 \%$ of respondents"; thus, 'perceived efficiency' was coded as +2. Furthermore, Li et al. [27] quantitatively tested nine hypotheses to examine people's willingness to adopt solar systems. Their study applied linear regression to investigate the impact of the independent variables on willingness. They found that switching cost had a significant negative relationship with

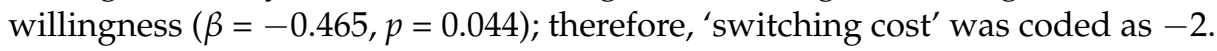

\section{Predictors of Solar Hot Water Adoption Behaviour}

The review of 100 research studies led to the identification of 123 techno-economic predictors of residential SWH adoption behaviour. These predictors evaluated households' attitude towards SWH, RE, and solar technologies as well as their diffusion rates, intention, acceptance, willingness, and technology choice. Studies' specific variables relied on their research purpose, and on average, seven predictors were evaluated in each article. Economic and technical determinants varied in detail; some referred to general indicators, whereas others described the indicators in as much detail as possible. To purchase an SWH system, consumers deal with two underlying types of predictors, namely financial and technical, acquired through two sets of factors. Economic and technological variables were classified into seven main categories and six subcategories (Figure 3). Figure 3 demonstrates sequences of concepts and the interconnection of layers. This customised taxonomy was achieved on the basis of behavioural theories and contextual factors, and the variables were categorised into perceived knowledge and actual knowledge. In terms of frequency of use, the technical and financial classifications occurred 421 and 402 times, respectively. Although the economic category had 11 variables fewer than the other category, its frequency of use was just 19 less than the technical category, demonstrating the importance of economic predictors. Part of perceived knowledge comes from official and unofficial (interpersonal) data flows, such as experts, acquaintances, or mass media, which convey the message that ultimately shapes the individual's attitude (e.g., the perceived suitability of a house; Figure 4). In reality, when the uptake of SWHs is estimated, the individual's mindset is as vital as statistical data and scientific research. This is because the final decision is based on the household's cognition, not on raw input data. 


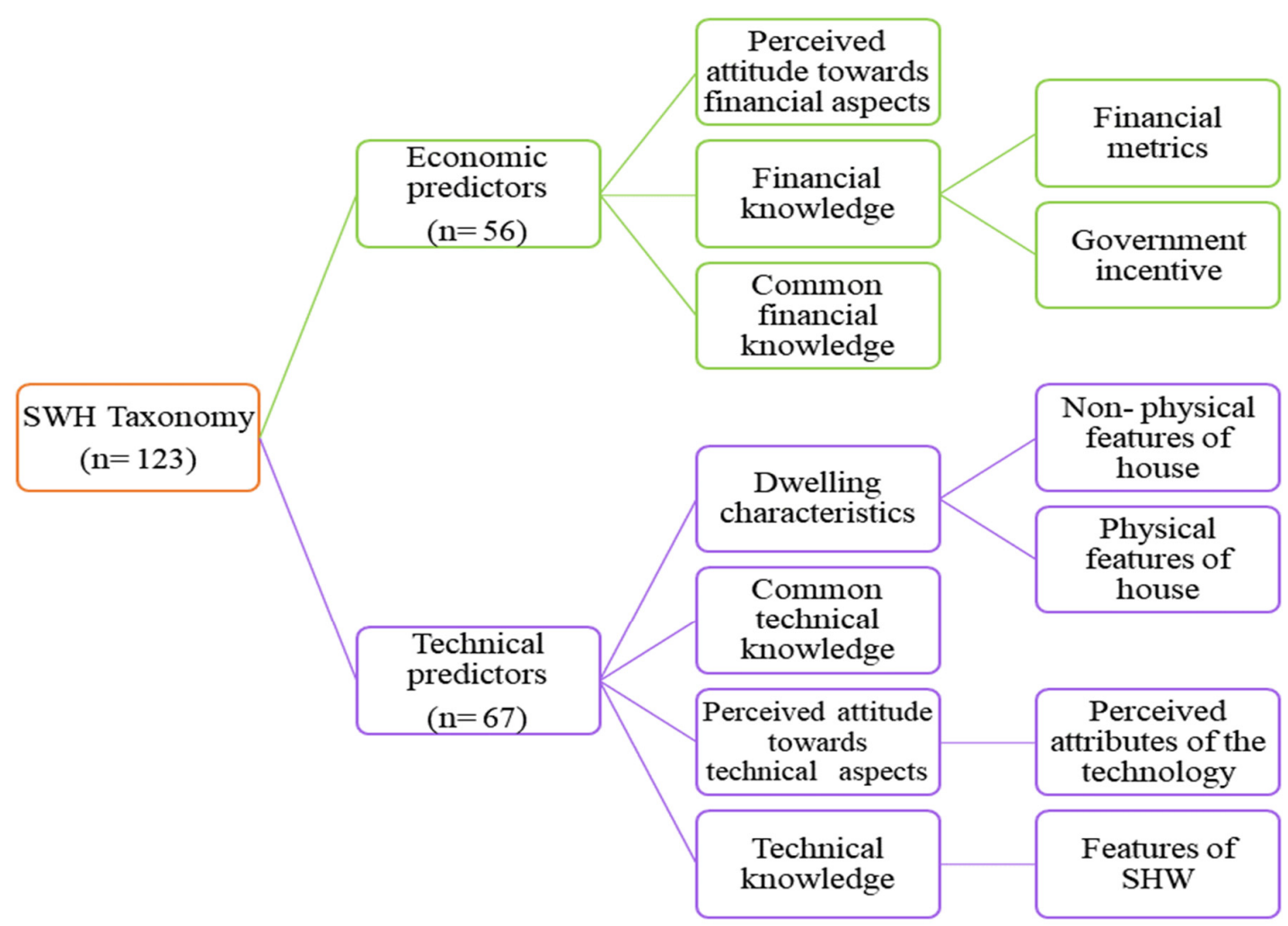

Figure 3. Taxonomy of solar adoption behaviour predictors by households in three layers ( $\mathrm{n}=$ number of predictors). The green rectangle illustrates economic predictors, and the purple ones represent technical predictors.

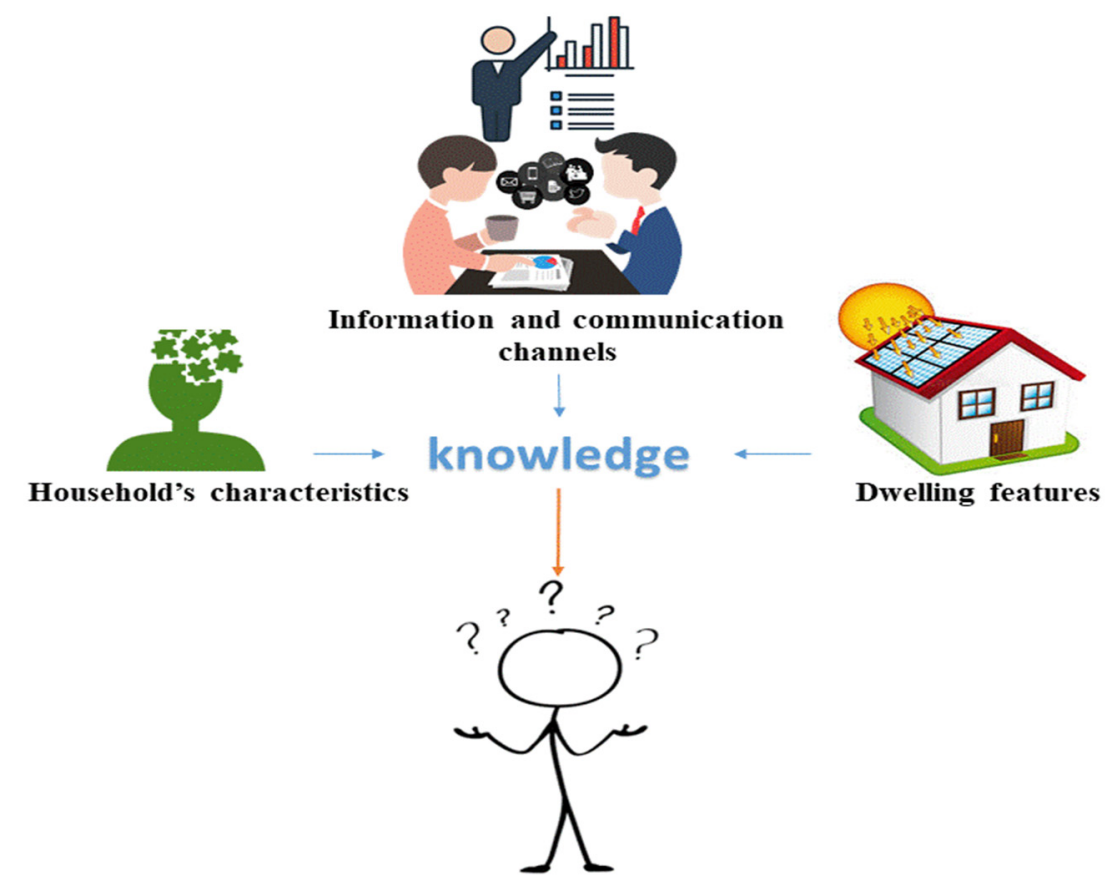

Figure 4. Influential information sources that shape individuals' attitudes.

The empirical studies mainly analysed perceived attitudes towards financial and technical aspects. They evaluated individuals' opinions, perceptions, and propensity [28,29]. Approximately 71 out of 100 studies examined perceived predictors which explains the great importance of people's mentality in the decision-making process. Some articles based on the modelling method synthesised personal characteristics in the measurement of fiscal 
concepts, such as 'financial vulnerability' [30] or 'perceived system cost' [31]. Descriptions of the reviewed technical and economic predictors, their frequency of use, and prominence status are discussed in the following subsections.

\subsection{Economic Predictors}

Fifty-six economic variables were extracted from 93 studies and categorised into three main categories and two subcategories. The relevant data is presented in Appendix A (Table A1). Financial knowledge revealed expenditure details (e.g., purchase, installation, and operations and maintenance (O\&M) costs), benefits of system adoption (e.g., bill and energy saving), and exogenous factors that influenced the fiscal aspects of buying an SWH (e.g., the cost of fossil fuel). The 'financial knowledge' category embraced a greater variety of predictors with two subcategories, namely financial metrics and governmental support. The former subcategory was generally used to give common economic information, whereas the latter subcategory evaluated the policies implemented by authorities to facilitate the purchase. By calculating the payback period [21,32-35] and other related scales $[9,36,37]$, financial metrics revealed that the technology is an investment with high initial costs $[35,38,39]$. The high purchase and installation expenditures negatively influence the adoption of these systems, leading to governmental support being the most common predictor in research. State financial motivations adjust the dynamics of total expenses by linking the gap between network power and solar costs and involve two incentive mechanisms: reducing purchase or installation prices [40-42] and alleviating RoI by applying FiT mechanisms [43-45]. Moreover, a relationship between 'financial incentives reducing purchase or installation costs and the adoption decision has repeatedly been found. Moreover, a relatively considerable association has been found between 'system cost' alongside 'payback period' and SWH acceptance. These were the most common fiscal factors that have been explored in both retroactive and prospective studies. They investigated the influential factors and predicted the most prominent determinants in the future diffusion of SWH systems. Furthermore, in terms of REs system diffusion, financial incentives are the main instruments of participation of the government. Although 'electricity price' and 'fossil fuel price' were subsets of the 'energy price' predictor, they were classified as separate variables. Some papers cited 'energy prices' in detail and in the form of 'fossil fuel price' and 'electricity price' $[21,37,44]$, whereas others explored the 'energy price' variable generally [46].

The category of perceived attitude towards financial aspects represents households' comprehension and appraisal of the economic gains and losses of SWH approval. In practice, no end-users easily understand the economic attributes. They are not particularly conscious of fiscal figures and do not thoroughly comprehend the explanations and economic details provided by experts. These predictors are shaped based on knowledge input through communication and information channels, people's beliefs, characteristics, and judgements about their house features (Figure 4). These approaches are not just sources of information; they shape the path and determine the imitators' final decision. Most determinants are perceived using a combination of data and cognition, whereas limited factors are detected with users' judgement, not based on their real data. Generally, when knowledge of a decision was evaluated, it became clear that by decreasing an individual's awareness, the importance of their perception and insight increases. Perceived attitude towards government policies and incentives was the most common factor among all categories and was surveyed in 32\% of studies [47-52]. As a whole, governmental policies and peoples' attitudes towards these supports were the most public predictors in both categories. The next most important predictors examined were households' attitudes towards the costs of adopting solar systems, such as 'system costs' [53], 'maintenance costs' [54], and 'upfront costs' [55] — these variables were included in at least $11 \%$ of studies. 'Common financial knowledge' embraced qualitative economic attributes and basic experience regarding solar system adoption. These popular parameters have commonly been employed in empirical research to assess fiscal education levels. This category's four variables were identified 
only eight times, with 'awareness of financial metrics used for calculating investment' mentioned three times as the primary predictor.

\subsection{Technical Predictors}

A total of 94 studies were reviewed to extract 67 technical predictors, which were split over the following four groups: technical knowledge, perceived attitude towards technical aspects, dwelling characteristics, and common technical knowledge. The relevant data is accessible in Appendix A in Table A2. Perceived technical attitude expounded on the residential beliefs about the system and technical market issues. These approaches were impenetrable experiences formed based on individuals' viewpoints and the hermeneutics of the received knowledge combined with individual features and beliefs, similar to perceived financial attitudes (Figure 4). Its larger subcategory, 'perceived features of the technology', uncovered people's beliefs regarding solar technology, not statistical data and real characteristics. Some variables such as 'perceived ease of use' were instinctively understood by the end-user [56], whereas some others were appreciated by gaining knowledge and cognition. 'Perceived attitudes towards technical aspects' identified in 56 of the reviewed papers assessed 26 predictors with a frequency of use of approximately $17 \%$. The knowledge and beliefs of decision-makers affected the levels of financial and technical attitudes; for example, the reasons for accepting SWHs provided by a specialist differed from those of an ordinary citizen with limited knowledge. The main predictor of this category for households was 'lack of knowledge', which occurred in 14 studies. It covered obtaining trustworthy and reliable information for accepting and using the system correctly [57].

The next significant category of adoption decisions for residential SWHs was 'dwelling characteristics'. This category involved both the physical and nonphysical details of the building. The physical attributes of a dwelling refer to the interior and exterior features of the building, such as roof type and number of rooms. The nonphysical factors measure solar radiation and some general traits such as house ownership. 'House type' was studied in approximately $30 \%$ of research and refers to the type of residential accommodation: detached, semi-detached, apartment, farm, or single story [58]. 'Geographical location' and 'solar radiation' were occasionally indicated in 22 and 15 studies, respectively, and were established among the first ranked factors after 'house type' in this category. A house's position is critical because it determines the amount of sunlight absorbed by solar panels. If the house is located in a low-sunlight area, the system's efficiency and its distribution decrease. The determination of 'geographical location' has mostly been used for Southeast Asian countries [21,34,59-61], which have a high level of solar radiation, whereas it has been used sparsely for the UK [62,63], Australia [64], and Ireland [65]. Even within a country, the amount of solar absorption may vary based on 'geographical location'; therefore, these two parameters were considered the most important indicators in most articles [44]. The technical characteristics of SWHs promoted the recognition of mechanical properties and the efficiency of technology through 10 predictors and $7 \%$ of repetitions. These predictors were parts of fiscal assessments for obtaining financial metrics in some econometric and prediction studies (commonly through 'system size' and 'efficiency of SWH' [37,44]). However, compared with financial factors, fewer studies used technical variables for statistical calculation. The predictor of 'solar collector', the main component of the system, was analysed in $9 \%$ of the studies. The predictors of 'SWH lifespan' and 'capacity', the next most popular technical factors, were investigated in fewer than 10 studies [34,46]. 'Common technical knowledge' covered the technical qualitative traits and usual necessary expertise regarding adoption behaviour. These prevailing predictors were generally adopted in the empirical research to evaluate technical knowledge levels. Eight factors in this category were used in 35 studies and identified 62 times, with 'awareness of SWHs' indicated 21 times as the leading predictor [66,67]. 


\section{Correlation of Predictors with the Adoption Decision}

A total of 399 votes were conducted and synthesised from two vote-counting exercises, namely economic and technical categories. Although both categories had the same size, the adoption decision was more significantly associated with economic predictors (Figure 5), and $57 \%$ of votes were recorded in this category. It contained more significant negative $(61 \%)$ and positive votes $(59 \%)$ than the technical category. It was observed that the technical category, despite having more subcategories, had fewer votes in all subcategories. Technical knowledge only had 12 significant votes, whereas perceived technical aspects had the most significantly negative votes ( 28 articles) in this category, and 'dwelling characteristic' variables were examined in 34 studies as significant positive predictors. Broadly speaking, all categories included more positive votes than negative, except the 'perceived attitude towards technical aspects' group ( 45 negative votes against 28 positive ones). The voting analysis focused on the most measured predictors to present a broad overview of the collected results. Predictors with one vote were excluded from the following calculation, and the full outcomes of vote-counting results for both categories are illustrated in the Supplementary Information File.

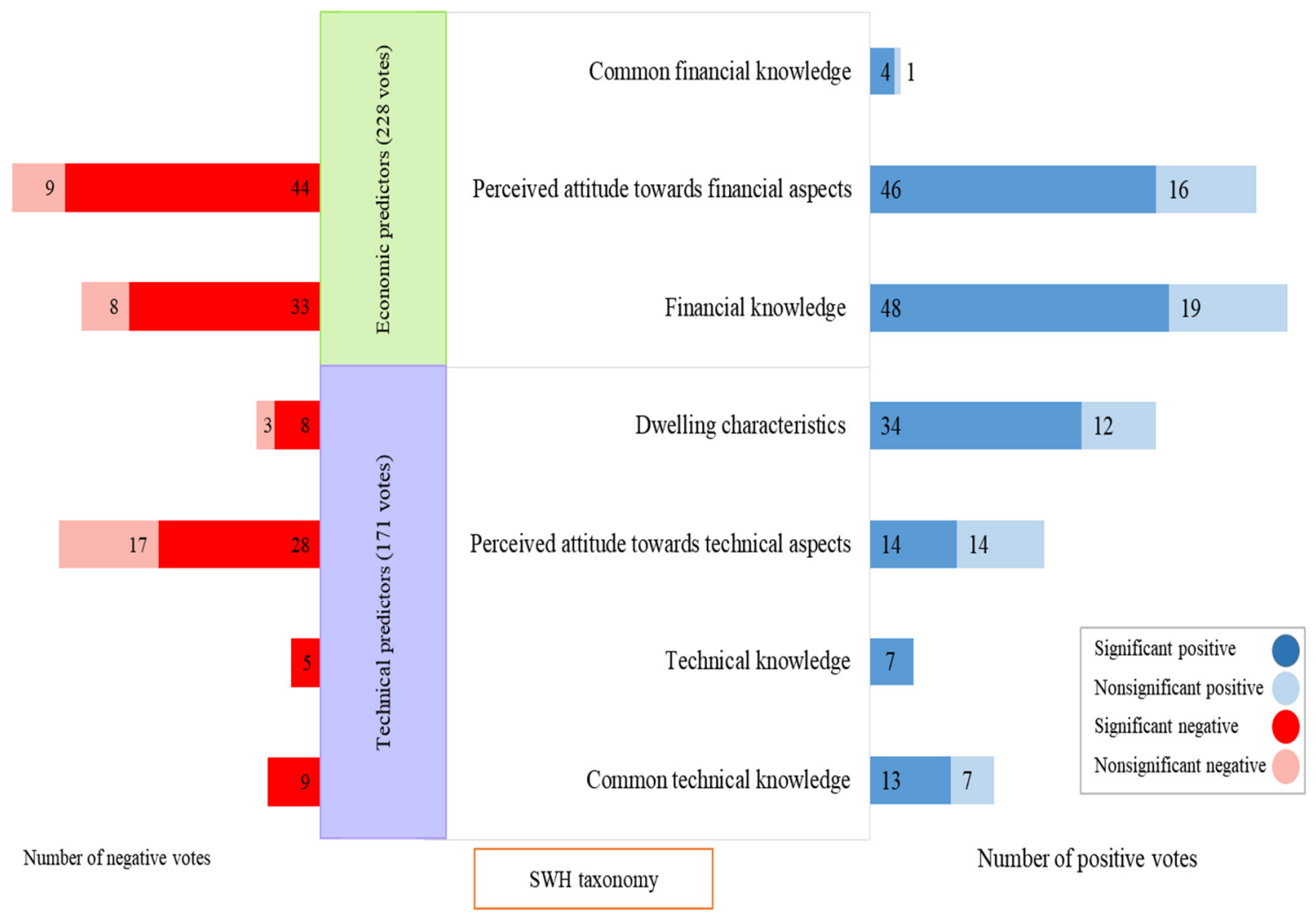

Figure 5. Overall vote-counting results of the main categories.

\subsection{Significance of Economic Predictors}

The analysis of 50 economic variables considered 228 votes in three categories with almost identical weights in two larger subgroups (Figure 6). The vote-counting results illustrated that government policies had a statistically significant association with residential system adoption. Moreover, $25 \%$ of the economic votes were allocated to both perceived and real government support, of which $23 \%$ confirmed the positive effects of these predictors, and only $2 \%$ recorded the negative impact. 'Perceived attitude of government policies' was analysed in fewer studies compared with 'government incentives' $(24<34)$ and had more negative votes $(5>1)$. Furthermore, $97 \%$ of the 'government incentives' subcategory had a positive correlation with solar system adoption. A study conducted in Karnataka, India, concluded that the $6-10 \%$ property tax rebate for $\mathrm{SWH}$ users was high. This tax 
decreased the willingness to accept the system, and should be reduced [52]. This study was the only negative vote in the governmental support subcategory; therefore, it must be seen whether it was in fact high or limited to that specific country and individuals' perception. Perceived costs in the form of 'installation costs' and 'upfront costs' were significantly negatively correlated with adoption at $100 \%$, whereas actual costs and the price of the system had a negative association in more than $83 \%$ of related studies. Kumar et al. stated that 'perceived cost' positively influenced customers' purchase intention to buy an SWH, and their positive correlation was confirmed by collecting data from 695 respondents in North India [66]. However, other studies that reviewed cost predictors found a negative correlation with adoption behaviour.

In the economic attributes category, although installation, system, and upfront costs had a lower correlation with the decision, 'energy cost' was significantly and negatively correlated in all studies that included it. Various reasons existed for this negative correlation. For instance, government fuel subsidies and the cheap cost of energy supplies reduced energy demand for RE systems such as SWHs [67,68]. Therefore, 'energy cost' had a significantly negative relationship with the adoption of solar systems. However, 'energy saving' and 'bill saving' in both categories were known to be significant positive motivations for households by all studies that considered them. 'Profitability', 'financial motivation', and 'increasing home values' had significantly positive associations with acceptance behaviour in less than $50 \%$ of studies. Generally, cost-related variables were negatively correlated with residential adoption, less in actual financial attributes than perceived economic variables. The smallest category, 'common financial knowledge', had a minor correlation with system adoption. The 'knowledge of incentives' was identified as a significant factor in only two papers.

\subsection{Technical Predictors}

The vote-counting exercise resulted in 171 technical votes in four separate groups (Figure 7). The largest group that included 73 votes was 'perceived attitude towards technical aspects', while 'technical knowledge' was the least significant category with only 12 votes. Predictors within the 'perceived technical attitudes' subcategory recorded approximately $43 \%$ of the technical votes. They were significantly connected to the adoption of SWHs. Although 'perceived appearance', 'structural damage of SWHs', and 'equipment and storage space' were negatively associated [23,58,63,66,69,70], 'perceived efficiency', 'perceived quality', and 'perceived system life' had absolute positive relationships [54,56,71] with system adoption. Perceived technology votes were significantly negative in more than $60 \%$ of measurements. The most prevalent factor was 'lack of knowledge', which was analysed in nine studies and regarded as a significantly negative vote in seven studies [72,73]. The vote-counting results were indecisive for 'safety' and 'complexity' [8,74].

The parameters of the 'dwelling characteristic' category (with 57 votes) had the highest positive correlation with solar adoption. All predictors' positive influences exceeded their adverse effects, except for the 'weather condition' variable, which had a significant but negative relationship, demonstrating their importance in the formation of solar adoption behaviour. For example, 'climatic conditions' (e.g., typhoon effect) were considered the major negative factors influencing the popularisation of SWHs in Taiwan [75]. 'House type' was the most potent factor in technical categories. It comprises all types of house such as detached, semi-detached, apartment, villa, and farms, and in some cases, it includes building materials [53,76]. In fact, 'house type' is an influential factor in the possibility of system installation. The 'technical knowledge' category was the smallest with only 12 votes. It discussed the level of effectiveness of professional technology predictors. For example, Mukwada et al. [77] stated that some residents prefer water pipes to be installed outside their houses instead of running along the interior walls because it could possibly cause dampness in the event of leakage, even though this could expose the water to a greater chance of freezing during winter. Moreover, the system's efficiency could be reduced due to the freezing of pipes or the lack of sunlight. Three-quarters of concepts under 'common 
technical knowledge' tended to have positive effects on adoption. This meant an increase in households' awareness of RE, incentives, SWHs, and its advantages and disadvantages, leading to increased demand for solar systems $[78,79]$.

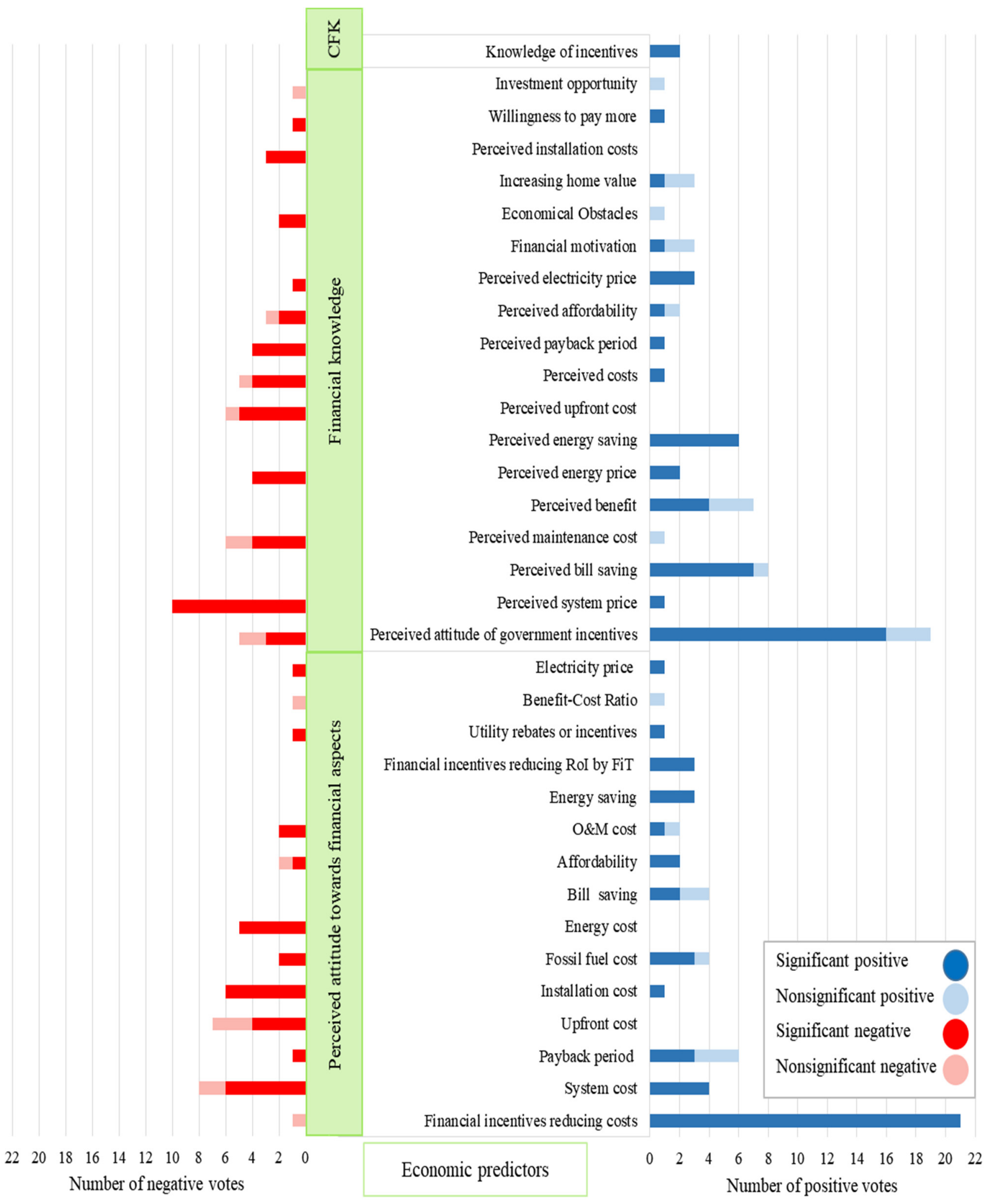

Figure 6. Vote-counting results for financial variables affecting solar system adoption by households. Results are narrowed to variables studied in at least two studies. 


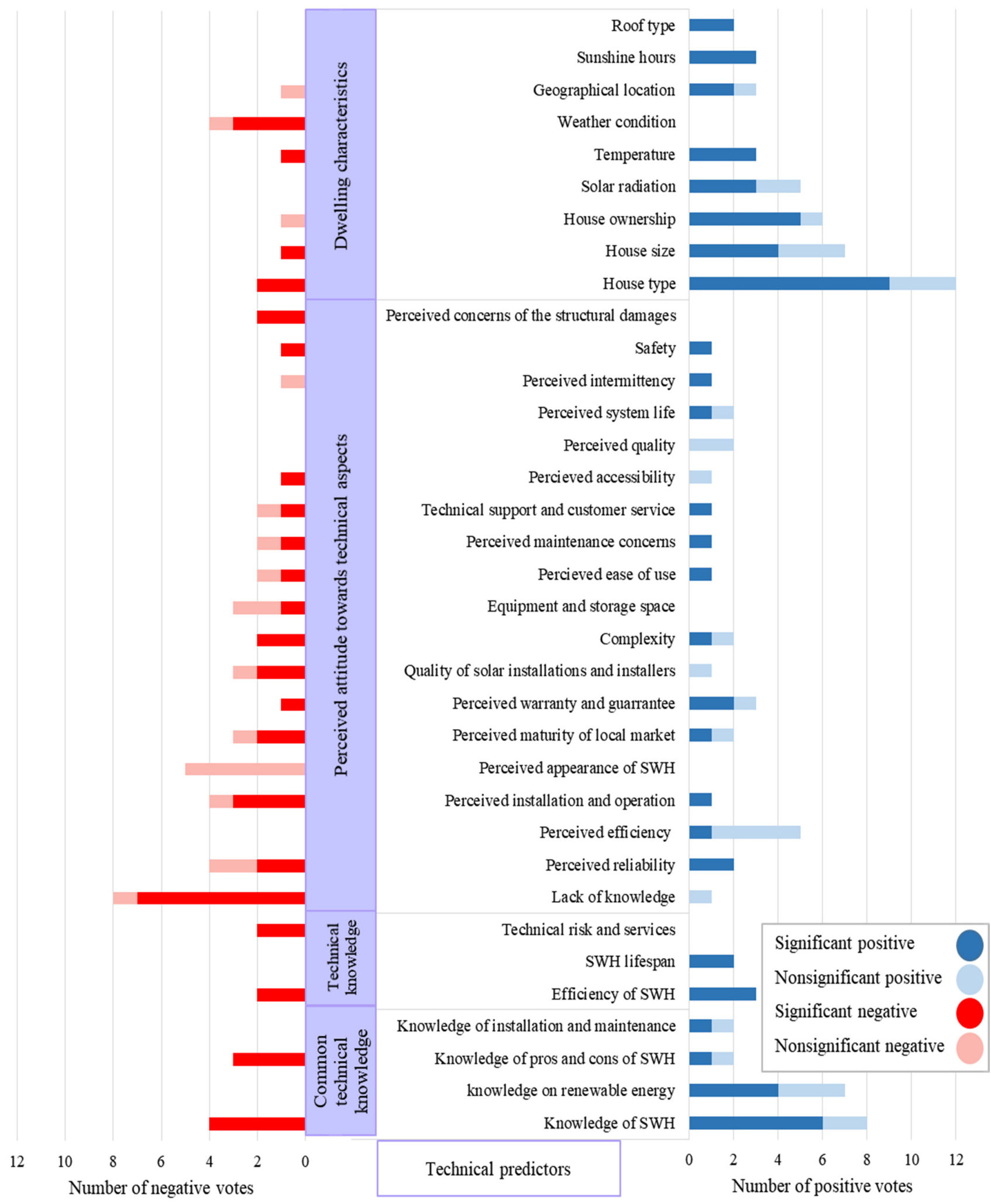

Figure 7. Vote-counting outcome for financial variables affecting the adoption of solar systems by households. Results are narrowed to variables studied in at least two studies.

\subsection{Comparison between SWH and SPV Adoption}

The researchers sought to understand the reasons for solar PV adoption in the domestic sector [11]. A comparison of the widespread trend of identical categories between PV 
and SWH systems revealed that the predictors of 'financial knowledge' and 'dwelling characteristics' have become more frequent in SPV expansion. However, SWH studies were found to broadly discuss technical variables more often. Perceived financial and technical knowledge contributed slightly more to homeowners' decision-making for SWH development. A detailed comparison of the essential parameters is discussed as follows (Figure 8).

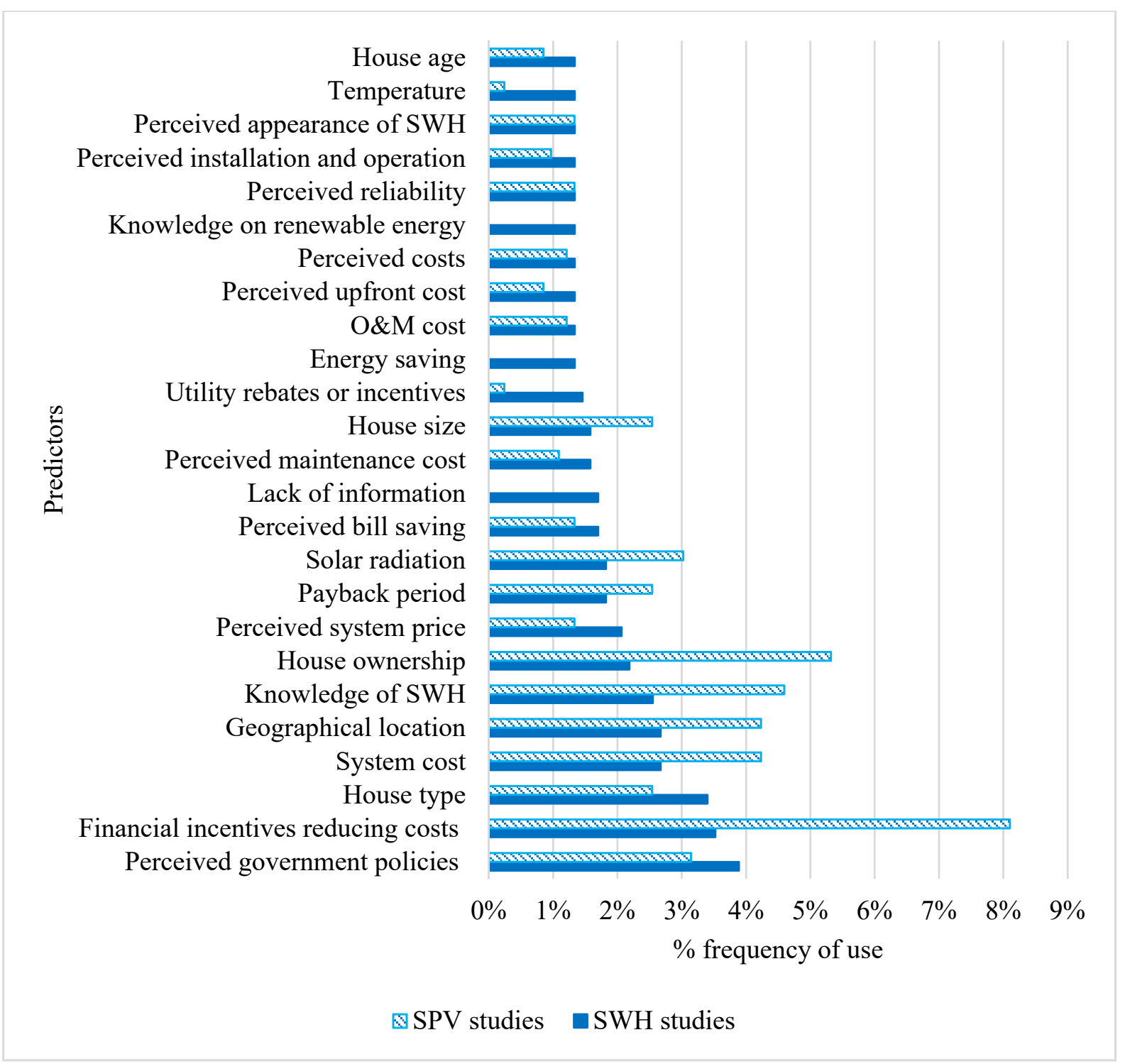

Figure 8. Comparison of the frequency of use among the SWH and SPV studies (data for SPV was adopted from [11]). The percentages were obtained as follows: (frequency of use for predictor $* 100$ )/(total number of frequency of use in all categories in associated studies).

'Electricity price' and its dependent variables were generally discussed further in SPV adoption studies due to their more significant impact on the 'payback period' and 'affordability'. Furthermore, an SPV system's capacity to store excess generated electricity was more decisive than a SWHs' capacity. By contrast, 'energy prices' (e.g., fossil fuel) was recognised as a crucial factor influencing SWH adoption compared with electricity.

'Government financial incentives' were known to be much more influential factors in SPV adoption compared with the SWH system. For example, the leasing option for SWH adoption was underestimated, whereas PV articles examined the leasing purchase parameters on the acceptance systems more. Leasing could be employed as an incentive 
in SWH development. Conversely, 'utility rebates or incentives' were discussed in only two SPV articles, although it is a famous concept in the development of SWH systems. The 'warranty and guarantee' concept was also missed in SPV analyses, whereas it was reviewed in seven SWH articles. One main reason for the low popularity of SWHs among households was demonstrated to be their 'lack of information', an indicator that was largely overlooked in SPV studies [11]. Increasing 'public awareness' of these systems' positive aspects can serve as a starting point for their expansion.

\section{Discussion and Concluding Remarks}

This study reviewed 100 articles on the technical and economic predictors that contribute to the residential adoption of SWHs. The original studies concentrated on the particular features of individuals' decisions and sought to discover the reasons for the households' actions and forecast future behaviours. The results revealed 123 predictors alongside their nature and origin. The findings further revealed the popularity of these factors and determined how and where they are often employed. This study introduced a comprehensive taxonomy customised for SWH adoption in the domestic sector for the identified predictors. The predictors in this taxonomy were divided into two main dimensions, seven categories, and six subcategories. A comparison of variables' frequency of use was also performed at the various taxonomy levels. The secondary objective was to differentiate the correlations between the 99 identified predictors and the adoption decision variables. The analysis stages helped to identify and evaluate the significance of the various predictors, which was the main study goal regarding the adoption of SWH technology.

\subsection{Economic Predictors Versus Technical Predictors}

Although numerous studies have classified household behaviour variables that concern information technology [13], technology-based products [16], sport [12], and medicine [14,15], only a few publications have considered both internal and external variables of adoption behaviour in the field of SPV technology [11]; furthermore, no studies have estimated both endogenous and exogenous concepts of the household decision in the adoption of SWH in residential sector. Although the article scope is limited to SWH and solar thermal, the framework is broadly appropriate to all solar and energy-efficiency technologies, and the identified predictors can be applied to all consumer behaviours in the residential sector. While some technical factors change, most economic factors remain valuable in other residential technologies. In this vein, the significant predictors identified in this article can give authors a good insight to identify technical and economic determinants of households in future studies. All of these parameters can be used as a starting point for future research.

By discriminating between the types of information input in the formation of the residential buyers' beliefs, the classification highlighted the importance of various influences and roles of accurate data and personal opinions. It also attempted to present a holistic insight into the whole picture of possible predictors and, in turn, more efficient determinant choices. The identified predictors comprised analysed concepts and unknown areas yet to be discovered. This comprehensive and synthesised review of appropriate predictors will make future studies more efficient and help policymakers decide on a broader vision. Although some parameters were similar in appearance, they could have different meanings in terms of concept. An accurate perception of a variable's concept had a great impact on its correct classification. As each of the predictors could enrich the list, they were not merged to emphasise common terms.

Investigations of the top-ranked determinants can be employed for the comparison of two main categories (Figure 9); 50\% of top-ranked indicators were located in the technical group, and the house characteristic subset included seven concepts. 'House type' and 'geographical location' were among the top five of all predictors. They illustrate the importance of house features in the decision-making process $[28,49,80]$. By contrast, 'common technical knowledge' and 'perceived attitudes towards technical aspects' were less common. Because 'technical knowledge' predictors are specialised, most individuals 
would not easily comprehend their direct effects and would not use technical information in their decision-making. They would often ask professional questions to experts and people who have previously used SWHs through various communication and information channels. Therefore, these technical variables fell more often into the perceived category, and none of the 'technical knowledge' predictors were observed in more than 10 articles. For example, 'perceived reliability' was reviewed in 11 articles, whereas 'reliability' was evaluated in only three articles [63,81-83].

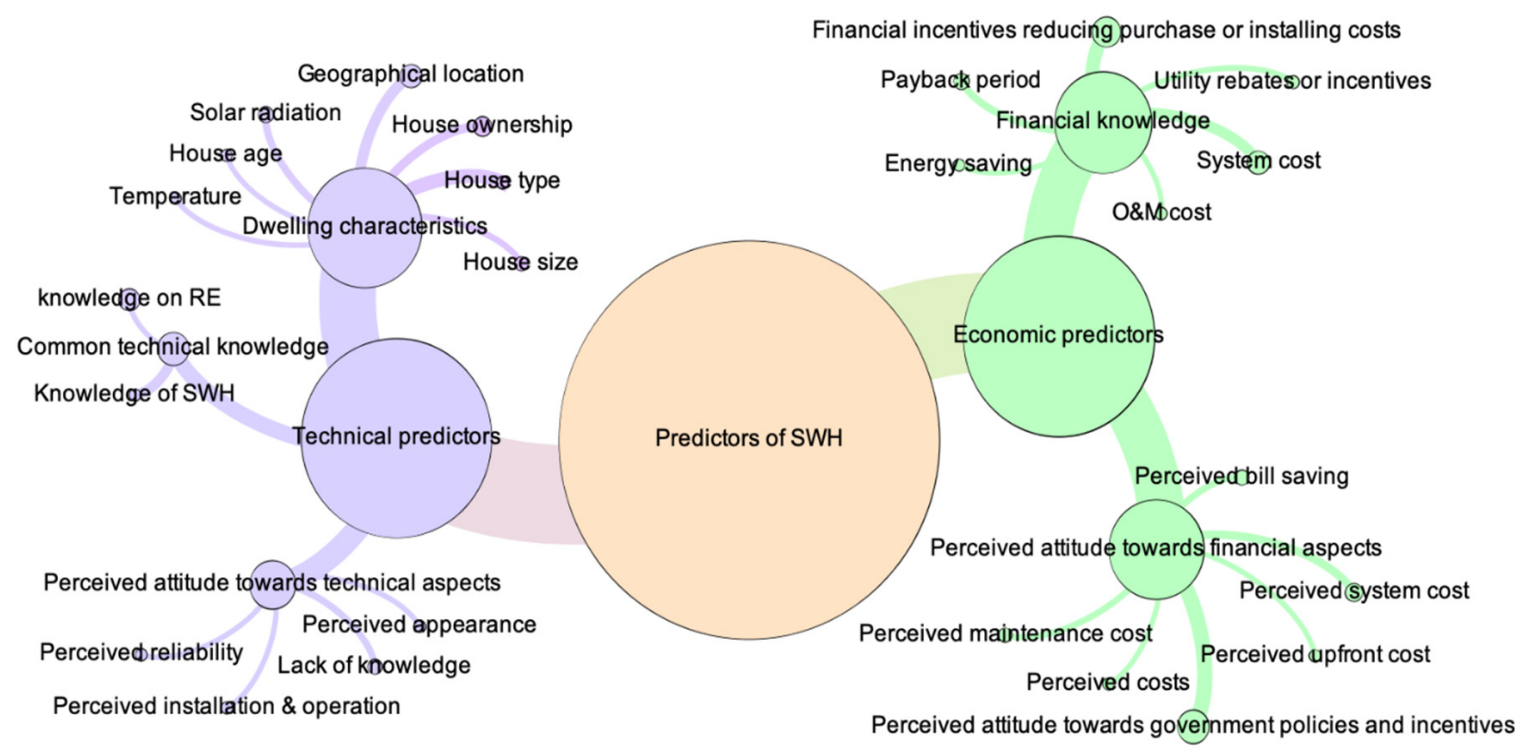

Figure 9. Comparison of the most frequently used predictors ( $>10$ articles). Green colour $=$ economic predictors, purple color $=$ technical predictors, larger circles $=$ more influential variables.

Furthermore, the participation rate of economic indicators was equal to the technical category in the top-ranked comparison. In each financial subgroup, the real and perceived legislative supports were the first ranked, and 'perceived attitude towards governmental policies' was the most common predictor and was frequently identified in 32 articles. Then, 'system costs' and 'perceived system costs' were identified as the next significant factors. Although the number of technical variables was more than that of financial variables, costs are more important than technical issues for decision-makers, and the repetition rate of fiscal predictors was slightly higher than that of technical predictors. Most individuals first consider system costs; then, if they can afford the system, they contemplate technical matters such as device efficiency.

The availability of financial data, especially government financial incentives (45\% of articles), led to financial variables being studied in the majority of articles. This was because government agencies sponsor many projects and articles, and policymakers want to know their duties in RE promotion. Moreover, government financial motivations are known to be more of a public benefit than other financial and technical indicators. People's decisions are more affected by government incentives than other categories such as 'dwelling characteristics'. Therefore, government incentives were examined in nearly half of the articles. In sum, governmental policies were determined to be among the most influential economic variables in SWH adoption. Globally, policymakers have succeeded in expanding these systems by applying fiscal incentive policies in the residential sector. These policy instruments have had significant effects on the horizontal axis of SWH development [51]. Tax deduction [84] and tax credit programs [85] have been estimated to be effective financial policy measures for promoting the diffusion of SWHs in the residential sector. Furthermore, low-interest finance mechanisms [43] and soft loan schemes [40] are among other appropriate financial intermediaries that authorities could consider in RE system deployment. 
In addition, the findings revealed that the most significant predictors were examined in the majority of studies. We found that approximately $60 \%$ of negative votes were allocated to perceived categories. This illustrates individuals' negative beliefs regarding solar systems and their financial dimensions, although statistical and specialised calculations revealed more positive aspects of SWHs and their reliability and affordability. As scepticism about solar systems reduces the likelihood of adoption [67], increasing consumers' knowledge through effective policy interventions can encourage uptake (Figure 4). The predictors of government support had the most significant and positive impact, whereas perceived government variables with more negative votes were considered in fewer studies. Intention to go for $\mathrm{SWH}$ is driven by the perceived attitudes towards the governmental policies. Therefore, a higher level of knowledge is required to be injected from both formal and interpersonal communication channels.

\subsection{Limitations and Future Research Recommendations}

A number of observations can be drawn about the limitations of the study. One concern is that the collected information was not specific to one country, and multiple terms were used to express the same concept according to different cultures. The same words not being used in different articles made the data collection more challenging, which was a major limitation. Furthermore, the frequency of use of the variables, subcategories, and groups indicated their popularity and capacity. Although the method used to determine the degree of repetition of influential predictors is proximate, the overall trend should be treated cautiously because some predictors were merged. Another limitation was that some predictors were correlated with others. As mentioned previously, many parameters introduced one concept (e.g., solar radiation) but had various manifestations. These were listed precisely because in some articles they were mentioned generally, whereas in others, they were stated in detail $[76,86]$.

Although residential SWH installation dates back more than five decades, approximately $50 \%$ of studies have been conducted during the past six years. This expanding enthusiasm should be maintained and disseminated. Behavioural studies that thoroughly consider parameters and models lead to an improved grasp of household behaviour. This review did not distinguish between the parameters of mature and immature markets in industrial and non-industrial countries. Future studies may consider the distinction of predictor type, their roles, and importance in the decision-making procedure based on their market and country conditions. Furthermore, determinants from retroactive and prospective studies were contemplated as the same factors in this study. Future studies need to examine the differences among applied predictors' selection and characteristics in each study type. Moreover, the theoretical frameworks' diversity and quality in the reviewed studies were largely limited. Future studies can apply this framework and methodology to the adoption of other innovations to specify the most important concepts and draw an entire picture of all RE technologies. In addition, this article did not address the dynamic connections between the economic and technical predictors to measure how they transform over time, as well as which parameters handle more shifts. The perception of behaviour becomes complex when the financial and technical characteristics of SWHs are incorporated into behavioural and social tendencies. Therefore, while current research has developed economic and technology predictors, future research could focus on social and individual predictors. 
Supplementary Materials: The following are available online at https:/ /www.mdpi.com/article/10 $.3390 /$ en14206630/s1, the searched keywords, four-phase assessment approach, temporal distribution of published research, list of reviewed papers, and full details of vote counting can be found in the Supplementary Information File.

Author Contributions: Conceptualization, S.G.Z. and M.A.; methodology, S.G.Z. and M.A.; software, S.G.Z. and R.P.T.; validation, S.G.Z., R.H., M.A. and R.A.S.; formal analysis, S.GH., R.H. and M.A.; investigation, M.A. and R.A.S.; resources, S.G.Z. and R.P.T.; data curation, S.G.Z. and M.A.; writingoriginal draft preparation, S.G.Z., R.H., M.A. and R.P.T.; writing-review and editing, R.H., M.A. and R.A.S.; visualization, S.G.Z., R.H. and R.P.T.; supervision, R.A.S.; project administration, S.G.Z. and M.A. All authors have read and agreed to the published version of the manuscript.

Funding: This research received no external funding.

Institutional Review Board Statement: Not applicable.

Informed Consent Statement: Not applicable.

Conflicts of Interest: The authors declare no conflict of interest. 


\section{Appendix A}

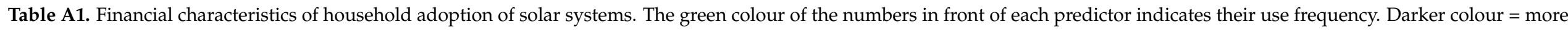
common in studies.

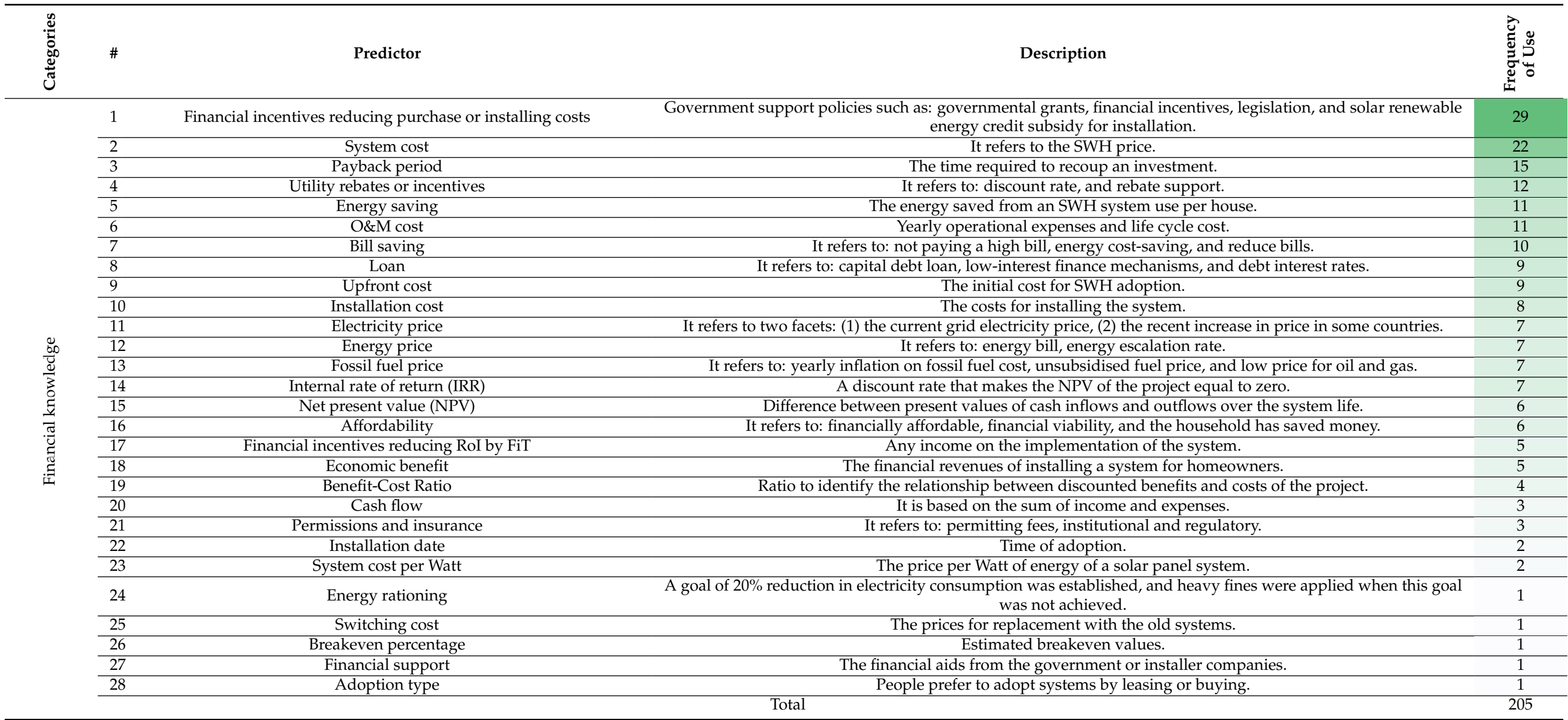


Table A1. Cont.

\begin{tabular}{|c|c|c|c|c|}
\hline 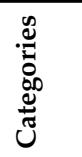 & $\#$ & Predictor & Description & 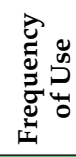 \\
\hline \multirow{25}{*}{ 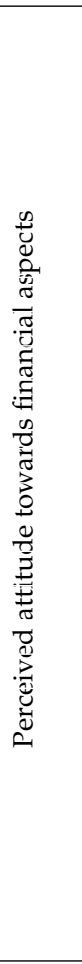 } & 29 & Perceived attitude towards government policies and incentives & $\begin{array}{l}\text { Attitude toward all incentives offered by the government such as FiT, government commitment, } \\
\text { government support, and all other financial incentives. }\end{array}$ & 32 \\
\hline & 30 & Perceived system cost & People's estimations for the SWH. & 17 \\
\hline & 31 & Perceived bill saving & $\begin{array}{l}\text { Households' beliefs about: save or earn money from lower fuel bills and government incentives, the } \\
\text { monetary benefit to end-users, and lower electricity bill. }\end{array}$ & 14 \\
\hline & 32 & Perceived maintenance cost & Approximate resources (cost) required for usage and maintenance. & 13 \\
\hline & 33 & Perceived upfront cost & Individuals believe in the initial cost of SWH adoption. & 11 \\
\hline & 34 & Perceived costs & The SWH costs such as O\&M, purchase cost, perceived high cost, and cost barrier. & 11 \\
\hline & 35 & Perceived energy price & People's beliefs towards the total costs of energy. & 10 \\
\hline & 36 & Perceived payback period & Households' viewpoint in the field of the required time to recoup an investment. & 9 \\
\hline & 37 & Perceived affordability & It refers to: good financial investment, financial viability, and economically feasible. & 9 \\
\hline & 38 & Perceived financial benefit & Individuals' approach in the profitability of SWH installing. & 7 \\
\hline & 39 & Investment opportunity & End-users think that SWH is an economic investment or not. & 7 \\
\hline & 40 & Financial motivation & Financial motives offered by utility companies, government, or installer. & 6 \\
\hline & 41 & Perceived electricity price & Concern over future electricity price. & 6 \\
\hline & 42 & Perceived fossil fuel price & Expectations on fuel prices. & 6 \\
\hline & 43 & Increasing home value & Perceived value of owner-occupied homes. & 6 \\
\hline & 44 & Economic obstacles & It refers to: economic obstacles, or not enough funds. & 4 \\
\hline & 45 & Perceived switching cost & It refers to: replacement for old systems, ability to relocate or change. & 4 \\
\hline & 46 & Perceived installation cost & Individuals' approach towards the costs of installing system process. & 4 \\
\hline & 47 & Obtaining best possible price & $\begin{array}{l}\text { Individuals assume that the SWH price is more reasonable than electricity and fuel, and by buying it, } \\
\text { they get the best energy supply cost. }\end{array}$ & 3 \\
\hline & 48 & Perceived fossil fuel consumption & A household belief that the usage of limited natural resources is reduced by adopting an SWH system. & 3 \\
\hline & 49 & Willingness to pay more & Willingness to pay an additional cost for SWH. & 2 \\
\hline & 50 & Financial vulnerability & Status of economic uncertainty or a position to the exposure of financial risk. & 2 \\
\hline & 51 & Attitude toward marketing factors & Attitudes towards the utility and installer companies. & 2 \\
\hline & 52 & Perceived income & Perceived financial situation of the household, and sufficient income to finance the installation. & 1 \\
\hline & & & Total & 189 \\
\hline \multirow{5}{*}{ 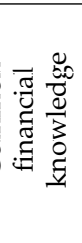 } & 53 & Knowledge of financial metrics used for calculating investment & It refers to: investment-relevant knowledge, a range of financial data for the solar water heater. & 3 \\
\hline & 54 & Knowledge of Security of investment & Households know the risk and security of investment. & 2 \\
\hline & 55 & Knowledge of incentives & $\begin{array}{c}\text { Decision-makers are aware of the incentives, availability of funds to pay upfront, and subsidy offered } \\
\text { by the government. }\end{array}$ & 2 \\
\hline & 56 & Knowledge of net-billing & $\begin{array}{l}\text { To understand the economic benefits that could be obtained by the adoption of SWH or awareness } \\
\text { about the cost of current fuel. }\end{array}$ & 1 \\
\hline & & & Total & 8 \\
\hline
\end{tabular}




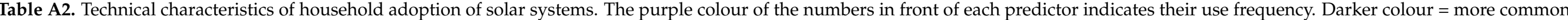
in studies.

\begin{tabular}{|c|c|c|c|c|}
\hline 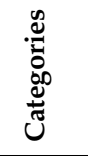 & $\#$ & Predictor & Description & 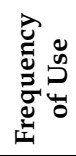 \\
\hline \multirow{11}{*}{ 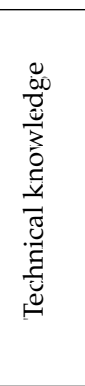 } & 1 & Solar collector & Type of solar collector, which determines its efficiency and other technical features. & 9 \\
\hline & 2 & SWH lifespan & It refers to: the life of the solar system, useful life, and operating lifetime. & 8 \\
\hline & 3 & SWH capacity & It refers to: capacity utilisation factor, and space usage. & 8 \\
\hline & 4 & Plumbing systems & It refers to: water circulation type, pipe frozen, and blocked-in winter. & 8 \\
\hline & 5 & System quality & It illustrates the quality of the systems offered by the installer. & 6 \\
\hline & 6 & Efficiency of SWH & It refers to: appropriateness of the technology, the current effective utilisation rate of SWHs in the domestic sector. & 6 \\
\hline & 7 & Technical risk and services & It refers to: System hazards, mistakes in the installation, and in a few cases to lack of maintenance. & 6 \\
\hline & 8 & Water storage tanks & Overhead water storage tanks that are suitable for the usage of SWH. & 4 \\
\hline & 9 & Reliability & It means that it is a reliable or unproven technology. & 3 \\
\hline & 10 & Warranty and guaranty & It refers to: warranty period in years, equipment guarantee period, and technical support. & 2 \\
\hline & & & Total & 60 \\
\hline \multirow{7}{*}{ 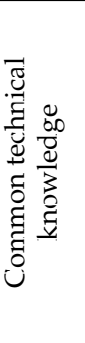 } & 11 & Knowledge of SWHs & $\begin{array}{c}\text { Energy literacy levels Including general and technical knowledge of SWH or negative images of solar water } \\
\text { heaters. }\end{array}$ & 21 \\
\hline & 12 & Knowledge of renewable energy & Individuals' information and research into REs. & 11 \\
\hline & 13 & Knowledge of pros and cons of SWH & Knowledge of people about the strengths and weaknesses of the system and its implementation. & 9 \\
\hline & 14 & Knowledge of operation & Presence of special requirements for the operation, education on system operation. & 4 \\
\hline & 15 & Knowledge of availability of technical support & Households do not have access to installation materials or experts to gain correct and sufficient information. & 3 \\
\hline & 18 & Knowledge of other energy sources & Other sources of energy than REs: oil, nuclear. & 2 \\
\hline & & & 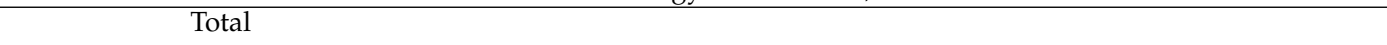 & 55 \\
\hline
\end{tabular}


Table A2. Cont.

\begin{tabular}{|c|c|c|c|c|}
\hline 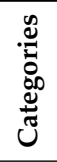 & $\#$ & Predictor & Description & 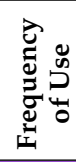 \\
\hline \multirow{26}{*}{ 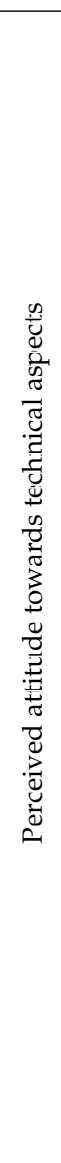 } & 19 & Lack of information & It means that peoples do not have correct and reliable information. & 14 \\
\hline & 20 & Perceived reliability & Consumers think that SWH is functionality and technologically reliable. & 11 \\
\hline & 21 & Perceived installation and operation & Users' ability towards installation and usage of SWH. & 11 \\
\hline & 22 & Perceived appearance of SWH & Opinions of households about the aesthetics of the device and its equipment. & 11 \\
\hline & 23 & Quality of solar installations and installers & Peoples believe that they have access to installation materials or expert human resources. & 10 \\
\hline & 24 & Complexity & $\begin{array}{l}\text { Complexity is the degree to which an innovation is perceived as relatively difficult to understand and to use. The } \\
\text { complexity of innovation, as perceived by members of a social system, is negatively related to its rate of adoption. }\end{array}$ & 8 \\
\hline & 25 & Perceived efficiency & It refers to: awareness and understanding of energy efficiency, and the energy efficiency of SWH. & 7 \\
\hline & 26 & Perceived quality & Domestic sector's opinion related to the quality control, quality of utilities provided, and water quality. & 7 \\
\hline & 27 & Perceived ease of use & Complexity of SWH system utilisation. & 6 \\
\hline & 28 & Perceived maturity of local market & $\begin{array}{l}\text { It refers to: availability of local installers or dealers, the problems of limited commercial systems, reputation of the } \\
\text { company, and imperfect competition with conventional technologies. }\end{array}$ & 6 \\
\hline & 29 & Perceived Equipment and storage space & The space required to install the system in people's opinion. & 5 \\
\hline & 30 & Perceived warranty and guaranty & People's beliefs and information about the warranty and guarantee of the system & 5 \\
\hline & 31 & Technical support and customer service & $\begin{array}{c}\text { Attitude towards the quality or importance of the technical support and service offered by the municipality or } \\
\text { installer to facilitate the technical conditions after-sale service. }\end{array}$ & 5 \\
\hline & 32 & Perceived Accessibility & $\begin{array}{l}\text { It refers to: unstable water supply or access to water. This is how easy it is to access energy-efficient devices, } \\
\text { which would be crucial for maintenance inspections, repairs, etc. }\end{array}$ & 4 \\
\hline & 34 & Perceived maintenance concerns & Users worry about how to maintain the device. & 4 \\
\hline & 35 & Perceived system life & System lifetime. & 3 \\
\hline & 36 & Safety & $\begin{array}{c}\text { Individuals believe that solar and SWH are safe energy sources in different weather conditions or the field of } \\
\text { health implications. }\end{array}$ & 3 \\
\hline & 37 & Brand image & Public opinion towards the company's manufacturing and installing the system. & 3 \\
\hline & 38 & Perceived durability & It is a durable system. & 2 \\
\hline & 39 & Structural damages & The high weight of the device and the water pipes leaking damage the building structure. & 2 \\
\hline & 40 & Perceived solar radiation received & $\begin{array}{c}\text { Households' evaluation towards the attracted solar radiation based on their house location and surrounding } \\
\text { conditions. }\end{array}$ & 2 \\
\hline & 41 & Technology obsolete & Some people think that the technology will become obsolete too quickly as difficulty in purchasing. & 2 \\
\hline & 42 & Ease of purchase & Purchase with interest-free instalments. & 1 \\
\hline & 43 & Perceived suitability of house & $\begin{array}{l}\text { People believe their house is suitable for installing an SWH based on climate conditions and home location (not } \\
\text { shaded by trees, chimneys, other buildings). }\end{array}$ & 1 \\
\hline & 44 & Perceived complexity of information & Failure to fully understand the techno-economic information provided by the installer or the government. & 1 \\
\hline & & & Total & 138 \\
\hline
\end{tabular}


Table A2. Cont.

\begin{tabular}{|c|c|c|c|c|}
\hline 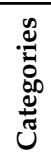 & \# & Predictor & Description & 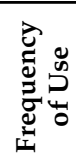 \\
\hline \multirow{22}{*}{ 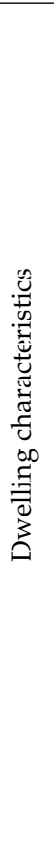 } & 45 & House type & $\begin{array}{l}\text { Type of residential accommodation such as thatched roof or other detached, middle of a row, semi-detached, } \\
\text { apartment, farm, single-family house, and villa, or type of building materials. }\end{array}$ & 28 \\
\hline & 46 & Geographical location & It affects the level of solar radiation received. & 22 \\
\hline & 47 & House ownership & It refers to: house-owner, renter, apartment owner, and etc. & 18 \\
\hline & 48 & Solar radiation & The amount of direct and indirect sunlight received. & 15 \\
\hline & 49 & House size & Dwelling size. & 13 \\
\hline & 51 & House age & Property age & 11 \\
\hline & 52 & Weather condition & It refers to: climate conditions, climate zone, and season indicators. & 8 \\
\hline & 53 & Sunshine hours & Average daily hours of sunshine. & 7 \\
\hline & 54 & Roof size & Available area in $\mathrm{m}^{2}$ for installation $\mathrm{SWH}$. & 5 \\
\hline & 55 & Suitability of house & Availability of a suitable installation area, matching of the system to location. & 5 \\
\hline & 56 & No. of rooms & The number of rooms in the house. & 4 \\
\hline & 57 & Roof type & Included: flat or pitched. & 3 \\
\hline & 58 & Roof insulation & Is the roof of the house insulated? & 3 \\
\hline & 59 & Energy efficiency & The energy efficiency of house. & 3 \\
\hline & 60 & Roof quality & The quality of the roof to install the system. & 2 \\
\hline & 62 & Roof space availability & Roof rights for residential accommodation. & 2 \\
\hline & 63 & House value & Median home value. & 2 \\
\hline & 64 & No. of bedrooms & Number of bedrooms in the house. & 1 \\
\hline & 65 & Pool in the house & Presence of pool at home. & 1 \\
\hline & 66 & Home/House repaired & Some people tend to adopt SWH while repairing their house. & 1 \\
\hline & 67 & Pleasant view & Visual and aesthetics. & 1 \\
\hline & & & Total & 168 \\
\hline
\end{tabular}




\section{References}

1. Hafezi, R.; Alipour, M. Renewable Energy Sources: Traditional and Modern Age Technologies. In Affordable and Clean Energy; Leal Filho, W., Azul, A.M., Brandli, L., Lange Salvia, A., Wall, T., Eds.; Springer International Publishing: Cham, Switzerland, 2020; pp. 1-15. [CrossRef]

2. Hafezi, R.; Alipour, M. Sustainable Energy Management. In Affordable and Clean Energy; Leal Filho, W., Azul, A.M., Brandli, L., Lange Salvia, A., Wall, T., Eds.; Springer International Publishing: Cham, Switzerland, 2020; pp. 1-13. [CrossRef]

3. Veeraboina, P.; Ratnam, G.Y. Analysis of the opportunities and challenges of solar water heating system (SWHS) in India: Estimates from the energy audit surveys \& review. Renew. Sustain. Energy Rev. 2012, 16, 668-676. [CrossRef]

4. Alipour, M.; Salim, H.; Stewart, R.A.; Sahin, O. Residential solar photovoltaic adoption behaviour: End-to-end review of theories, methods and approaches. Renew. Energy 2021. [CrossRef]

5. Alipour, M.; Hafezi, R.; Papageorgiou, E.; Hafezi, M.; Alipour, M. Characteristics and scenarios of solar energy development in Iran: Fuzzy cognitive map-based approach. Renew. Sustain. Energy Rev. 2019, 116, 109410. [CrossRef]

6. Alipour, M.; Stewart, R.A.; Sahin, O. Beyond the Diffusion of Residential Solar Photovoltaic Systems at Scale: Allegorising the Battery Energy Storage Adoption Behaviour. Energies 2021, 14, 5015. [CrossRef]

7. Wang, X.; Xiong, Y.; Yang, R.; Yu, P. Social Psychological Predictors of Adoption Intention for Solar Water Heaters in Rural China. Soc. Behav. Personal. 2019, 47, 1-13. [CrossRef]

8. Naidoo, A. The socio-economic impacts of solar water heaters compared across two communities: A case study of Cato Manor. Renew. Sustain. Energy Rev. 2020, 119, 109525. [CrossRef]

9. Cruz, T.; Schaeffer, R.; Lucena, A.F.P.; Melo, S.; Dutra, R. Solar water heating technical-economic potential in the household sector in Brazil. Renew. Energy 2020, 146, 1618-1639. [CrossRef]

10. Ntanos, S.; Kyriakopoulos, G.; Chalikias, M.; Arabatzis, G.; Skordoulis, M. Public Perceptions and Willingness to Pay for Renewable Energy: A Case Study from Greece. Sustainability 2018, 10, 687. [CrossRef]

11. Alipour, M.; Salim, H.; Stewart, R.A.; Sahin, O. Predictors, taxonomy of predictors, and correlations of predictors with the decision behaviour of residential solar photovoltaics adoption: A review. Renew. Sustain. Energy Rev. 2020, 123, 109749. [CrossRef]

12. Blank, C.; Kopp, M.; Niedermeier, M.; Schnitzer, M.; Schobersberger, W. Predictors of doping intentions, susceptibility, and behaviour of elite athletes: A meta-analytic review. SpringerPlus 2016, 5, 1-14. [CrossRef] [PubMed]

13. Jeyaraj, A.; Rottman, J.W.; Lacity, M.C. A Review of the Predictors, Linkages, and Biases in IT Innovation Adoption Research. J. Inf. Technol. 2006, 21, 1-23. [CrossRef]

14. Varabyova, Y.; Blankart, C.R.; Greer, A.L.; Schreyögg, J. The determinants of medical technology adoption in different decisional systems: A systematic literature review. Health Policy 2017, 121, 230-242. [CrossRef] [PubMed]

15. Turner, C.; O'Gorman, B.; Nair, A.; O'Kearney, R. Moderators and predictors of response to cognitive behaviour therapy for pediatric obsessive-compulsive disorder: A systematic review. Psychiatry Res. 2018, 261, 50-60. [CrossRef] [PubMed]

16. Satapathy, S.; Sangle, S.; Unnikrishnan, S. Determinants of technology-based product adoption by consumers. World Rev. Sci. Technol. Sustain. Dev. 2018, 14, 85-99. [CrossRef]

17. Moher, D.; Liberati, A.; Tetzlaff, J.; Altman, D.G. Preferred Reporting Items for Systematic Reviews and Meta-Analyses: The PRISMA Statement. Ann. Intern. Med. 2009, 151, 264-269. [CrossRef]

18. Pickering, C.; Grignon, J.; Steven, R.; Guitart, D.; Byrne, J. Publishing not perishing: How research students transition from novice to knowledgeable using systematic quantitative literature reviews. Stud. High. Educ. 2015, 40, 1756-1769. [CrossRef]

19. Cheng, M.; Edwards, D.; Darcy, S.; Redfern, K. A Tri-Method Approach to a Review of Adventure Tourism Literature: Bibliometric Analysis, Content Analysis, and a Quantitative Systematic Literature Review. J. Hosp. Tour. Res. 2016, 42, 997-1020. [CrossRef]

20. Phan, T.D.; Smart, J.C.R.; Capon, S.J.; Hadwen, W.L.; Sahin, O. Applications of Bayesian belief networks in water resource management: A systematic review. Environ. Model. Softw. 2016, 85, 98-111. [CrossRef]

21. Rout, A.; Sahoo, S.; Thomas, S.; Varghese, S. Development of Customized Formulae for Feasibility and Break-Even Analysis of Domestic Solar Water Heater. Int. J. Renew. Energy Res. 2017, 7, 386-398.

22. Yuan, X.; Zuo, J.; Ma, C. Social acceptance of solar energy technologies in China-End users' perspective. Energy Policy 2011, 39, 1031-1036. [CrossRef]

23. Alrashed, F.; Asif, M. An Exploratory of Residents' Views Towards Applying Renewable Energy Systems in Saudi Dwellings. Energy Procedia 2015, 75, 1341-1347. [CrossRef]

24. Bushman, B.; Wang, M.C. Vote-counting procedures in meta-analysis. Handb. Res. Synth. 1994, 236, $193-213$.

25. Kahiya, E.T. Five decades of research on export barriers: Review and future directions. Int. Bus. Rev. 2018, 27, 1172-1188. [CrossRef]

26. Balezentis, T.; Streimikiene, D.; Mikalauskas, I.; Shen, Z. Towards carbon free economy and electricity: The puzzle of energy costs, sustainability and security based on willingness to pay. Energy 2021, 214, 119081. [CrossRef]

27. Li, X.; Li, H.; Wang, X. Farmers' willingness to convert traditional houses to solar houses in rural areas: A survey of 465 households in Chongqing, China. Energy Policy 2013, 63, 882-886. [CrossRef]

28. Matsumoto, S. Household Income Structure and Electrical Appliance Ownership: Evidence from Japanese National Household Survey. Int. J. Energy Econ. Policy 2016, 6, 14-19. 
29. Refalo, P.; Mulè Stagno, L.; Farrugia, R.N.; Yousif, C.; Sant, T.; Jakkel, N.; Zammit, A.; Portelli, J. The ‘Reduce and Save’ Project: An Island-Wide Resource Management Awareness Initiative. In Mediterranean Green Buildings E Renewable Energy; Springer: Cham, Switzerland, 2017; pp. 811-820.

30. Moglia, M.; Podkalicka, A.; James, M. An Agent-Based Model of Residential Energy Efficiency Adoption. J. Artif. Soc. Soc. Simul. 2018, 21, 3. [CrossRef]

31. Jeong, G. Assessment of government support for the household adoption of micro-generation systems in Korea. Energy Policy 2013, 62, 573-581. [CrossRef]

32. Yamaguchi, Y.; Akai, K.; Shen, J.; Fujimura, N.; Shimoda, Y.; Saijo, T. Prediction of photovoltaic and solar water heater diffusion and evaluation of promotion policies on the basis of consumers' choices. Appl. Energy 2013, 102, 1148-1159. [CrossRef]

33. Salgado-Conrado, L.; Lopez-Montelongo, A. Barriers and solutions of solar water heaters in Mexican household. Sol. Energy 2019, 188, 831-838. [CrossRef]

34. Yaqoot, M.; Diwan, P.; Kandpal, T. Financial attractiveness of decentralized renewable energy systems-A case of the central Himalayan state of Uttarakhand in India. Renew. Energy 2017, 101, 973-991. [CrossRef]

35. Özdemir, E.D.; Marathe, S.D.; Tomaschek, J.; Dobbins, A.; Eltrop, L. Economic and environmental analysis of solar water heater utilisation in Gauteng Province, South Africa. J. Energy South. Afr. 2012, 23, 2-19. [CrossRef]

36. Cesta, J.R.; Decker, P.G. Speeding solar energy commercialization: A Delphi research of marketplace factors. J. Bus. Res. 1978, 6, 311-328. [CrossRef]

37. Lugaric, L.; Skrlec, D.; Krajcar, S. Household Solar Water Heating System Investment Modelling and Risk Analysis. In Proceedings of the EUROCON 2007-The International Conference on "Computer as a Tool", Warsaw, Poland, 9-12 September 2007; pp. 841-848.

38. Chang, K.; Lee, T.; Chung, K. Solar water heaters in Taiwan. Renew. Energy 2006, 31, 1299-1308. [CrossRef]

39. Chang, K.-C.; Lin, W.-M.; Ross, G.; Chung, K.-M. Dissemination of solar water heaters in South Africa. J. Energy South. Afr. 2011, 22, 2-7. [CrossRef]

40. Yaqoot, M.; Kandpal, T. Potential of Renewable Energy System Utilization at Decentralized Level in the State of Uttarakhand in India. Int. J. Ambient Energy 2018, 41, 1-27. [CrossRef]

41. Lin, W.-M.; Chang, K.-C.; Chung, K.-M. The Impact of Subsidy Programs for Solar Thermal Applications: A Case Study for a Remote Island. Energies 2019, 12, 3944. [CrossRef]

42. Su, W.; Liu, M.; Zeng, S.; Štreimikienè, D.; Baležentis, T.; Ališauskaitė-Šeškienè, I. Valuating renewable microgeneration technologies in Lithuanian households: A study on willingness to pay. J. Clean. Prod. 2018, 191, 318-329. [CrossRef]

43. Saunders, R.W.; Gross, R.J.K.; Wade, J. Can premium tariffs for micro-generation and small scale renewable heat help the fuel poor, and if so, how? Case studies of innovative finance for community energy schemes in the UK. Energy Policy 2012, 42, 78-88. [CrossRef]

44. Stevanović, S.; Pucar, M. Financial measures Serbia should offer for solar water heating systems. Energy Build. 2012, 54, 519-526. [CrossRef]

45. Simpson, G.; Clifton, J. The emperor and the cowboys: The role of government policy and industry in the adoption of domestic solar microgeneration systems. Energy Policy 2015, 81, 141-151. [CrossRef]

46. Absemetov, A.; Mukushev, M.; Yerubayev, A.; Zhumanalina, Z.; Rojas-Solórzano, L. Effectiveness and Prospects of Implementing a Solar Water Heating System in Astana, Kazakhstan. In The Role of Exergy in Energy and the Environment; Springer: Cham, Switzerland, 2018; pp. 603-615. [CrossRef]

47. Elmustapha, H.; Hoppe, T.; Bressers, H. Consumer renewable energy technology adoption decision-making; comparing models on perceived attributes and attitudinal constructs in the case of solar water heaters in Lebanon. J. Clean. Prod. 2018, 172, 347-357. [CrossRef]

48. Reddy, S.; Painuly, J.P. Diffusion of renewable energy technologies-Barriers and stakeholders' perspectives. Renew. Energy 2004, 29, 1431-1447. [CrossRef]

49. Aydin, E.; Eichholtz, P.; Yönder, E. The economics of residential solar water heaters in emerging economies: The case of Turkey. Energy Econ. 2018, 75, 285-299. [CrossRef]

50. Chen, C.-f.; Xu, X.; Frey, S. Who wants solar water heaters and alternative fuel vehicles? Assessing social-psychological predictors of adoption intention and policy support in China. Energy Res. Soc. Sci. 2016, 15, 1-11. [CrossRef]

51. Jridi, O.; Aguir Bargaoui, S.; Nouri, F.Z. Household preferences for energy saving measures: Approach of discrete choice models. Energy Build. 2015, 103, 38-47. [CrossRef]

52. Sakri, S.G.; Jayaramaiah, G.V. Study of consumer's willingness to use solar water heaters in DSM program. In Proceedings of the 2013 IEEE 7th International Power Engineering and Optimization Conference (PEOCO), Langkawi, Malaysia, 3-4 June 2013; pp. $478-482$.

53. Saleh, A.; Haris, A.; Ahmad, N. Towards a UTAUT-based model for the intention to use solar water heaters by Libyan households. Int. J. Energy Econ. Policy 2014, 4, 26-31.

54. van Blommestein, K.; Daim, T. Residential Energy Efficient Device Adoption in South Africa. Sustain. Energy Technol. Assess. 2013, 1, 13-27. [CrossRef]

55. Labay, D.G.; Kinnear, T.C. Exploring the Consumer Decision Process in the Adoption of Solar Energy Systems. J. Consum. Res. 1981, 8, 271-278. [CrossRef] 
56. Michelsen, C.C.; Madlener, R. Motivational factors influencing the homeowners' decisions between residential heating systems: An empirical analysis for Germany. Energy Policy 2013, 57, 221-233. [CrossRef]

57. Baskaran, R.; Managi, S.; Bendig, M. A public perspective on the adoption of microgeneration technologies in New Zealand: A multivariate probit approach. Energy Policy 2013, 58, 177-188. [CrossRef]

58. Willis, K.; Scarpa, R.; Gilroy, R.; Hamza, N. Renewable energy adoption in an ageing population: Heterogeneity in preferences for micro-generation technology adoption. Energy Policy 2011, 39, 6021-6029. [CrossRef]

59. Chang, K.-C.; Lin, W.-M.; Chung, K.-M. A lesson learned from the long-term subsidy program for solar water heaters in Taiwan. Sustain. Cities Soc. 2018, 41, 810-815. [CrossRef]

60. Ma, B.; Song, G.; Smardon, R.C.; Chen, J. Diffusion of solar water heaters in regional China: Economic feasibility and policy effectiveness evaluation. Energy Policy 2014, 72, 23-34. [CrossRef]

61. Lim, S.; Huh, S.-Y.; Shin, J.; Lee, J.; Lee, Y.-G. Enhancing public acceptance of renewable heat obligation policies in South Korea: Consumer preferences and policy implications. Energy Econ. 2019, 81, 1167-1177. [CrossRef]

62. Balcombe, P.; Rigby, D.; Azapagic, A. Investigating the importance of motivations and barriers related to microgeneration uptake in the UK. Appl. Energy 2014, 130, 403-418. [CrossRef]

63. Caird, S.; Roy, R. Adoption and Use of Household Microgeneration Heat Technologies. Low Carbon Econ. 2010, 1, 61-70. [CrossRef]

64. Higgins, A.; Foliente, G. Evaluating intervention options to achieve environmental benefits in the residential sector. Sustain. Sci. 2013, 8, 25-36. [CrossRef]

65. Claudy, M.C.; Michelsen, C.; O'Driscoll, A.; Mullen, M.R. Consumer awareness in the adoption of microgeneration technologies: An empirical investigation in the Republic of Ireland. Renew. Sustain. Energy Rev. 2010, 14, 2154-2160. [CrossRef]

66. Kumar, V.; Syan Amanjot, S.; Kaur, K. A structural equation modeling analysis of factors driving customer purchase intention towards solar water heater. Smart Sustain. Built Environ. 2020. ahead-of-print. [CrossRef]

67. Yuasa, K.; Yata, M. Installation of Residential Energy Systems: Local Conditions and Residents' Willingness. J. Asian Archit. Build. Eng. 2016, 15, 127-132. [CrossRef]

68. Urmee, T.; Walker, E.; Bahri, P.A.; Baverstock, G.; Rezvani, S.; Saman, W. Solar water heaters uptake in Australia-Issues and barriers. Sustain. Energy Technol. Assess. 2018, 30, 11-23. [CrossRef]

69. Faiers, A.; Neame, C. Consumer attitudes towards domestic solar power systems. Energy Policy 2006, 34, 1797-1806. [CrossRef]

70. Caird, S.; Roy, R.; Herring, H. Improving the energy performance of UK households: Results from surveys of consumer adoption and use of low- and zero carbon technologies. Energy Effic. 2008, 1, 149. [CrossRef]

71. Sidiras, D.K.; Koukios, E.G. Solar systems diffusion in local markets. Energy Policy 2004, 32, 2007-2018. [CrossRef]

72. Bergman, N. Why is renewable heat in the UK underperforming? A socio-technical perspective. Proc. Inst. Mech. Eng. Part A J. Power Energy 2013, 227, 124-131. [CrossRef]

73. Sharifi, M.; Khazaei Pool, J.; Jalilvand, M.R.; Tabaeeian, R.A.; Ghanbarpour Jooybari, M. Forecasting of advertising effectiveness for renewable energy technologies: A neural network analysis. Technol. Forecast. Soc. Chang. 2019, 143, 154-161. [CrossRef]

74. Foster, J. Solar Water Heating in Queensland: The Roles of Innovation Attributes, Attitudes and Information in the Adoption Process. Prometheus 1993, 11, 219-233. [CrossRef]

75. Wang, X.; Guan, Z.; Wu, F. Solar energy adoption in rural China: A sequential decision approach. J. Clean. Prod. 2017, 168, 1312-1318. [CrossRef]

76. Mukwada, G.; Chingombe, W.; Taru, P. Why Social Acceptance in South African Solar Water Heater Projects Should Shape National Energy Policy: The Case of Bluegumbosch. Mediterr. J. Soc. Sci. 2014, 5, 635. [CrossRef]

77. Zografakis, N.; Sifaki, E.; Pagalou, M.; Nikitaki, G.; Psarakis, V.; Tsagarakis, K.P. Assessment of public acceptance and willingness to pay for renewable energy sources in Crete. Renew. Sustain. Energy Rev. 2010, 14, 1088-1095. [CrossRef]

78. Liu, W.; Wang, C.; Mol, A.P.J. Rural public acceptance of renewable energy deployment: The case of Shandong in China. Appl. Energy 2013, 102, 1187-1196. [CrossRef]

79. Karytsas, S.; Vardopoulos, I.; Theodoropoulou, E. Factors Affecting Sustainable Market Acceptance of Residential Microgeneration Technologies. A Two Time Period Comparative Analysis. Energies 2019, 12, 3298. [CrossRef]

80. Kanyarusoke, K. Problems of engineering entrepreneurship in Africa: A design optimization example in solar thermal engineering. Eng. Sci. Technol. Int. J. 2020, 23, 345-356. [CrossRef]

81. Amer, M.; Daim, T.U. Selection of renewable energy technologies for a developing county: A case of Pakistan. Energy Sustain. Dev. 2011, 15, 420-435. [CrossRef]

82. Hast, A.; Alimohammadisagvand, B.; Syri, S. Consumer attitudes towards renewable energy in China-The case of Shanghai. Sustain. Cities Soc. 2015, 17, 69-79. [CrossRef]

83. Sardianou, E.; Genoudi, P. Which factors affect the willingness of consumers to adopt renewable energies? Renew. Energy 2013, 57, 1-4. [CrossRef]

84. Nasirov, S.; Carredano, N.; Agostini, C.A.; Silva, C. Public perception and adoption of Solar Water Heating systems in Chile: The role of supply side income tax credits. Renew. Sustain. Energy Rev. 2021, 135, 110389. [CrossRef]

85. Chang, K.-C.; Lee, T.-S.; Lin, W.-M.; Chung, K.-M. Outlook for solar water heaters in Taiwan. Energy Policy 2008, 36, 66-72. [CrossRef]

86. Uken, E. Policy Pitfalls of SWH. Energy Procedia 2012, 30, 1432-1434. [CrossRef] 